Cognitive Science 45 (2021) e12987

(C) 2021 The Authors. Cognitive Science published by Wiley Periodicals LLC on behalf of Cognitive Science Society (CSS). All rights reserved.

ISSN: 1551-6709 online

DOI: $10.1111 / \operatorname{cogs} .12987$

\title{
Human Self-Domestication and the Evolution of Pragmatics
}

\author{
Antonio Benítez-Burraco, ${ }^{\mathrm{a}}$ () Francesco Ferretti, ${ }^{\mathrm{b}}$ Ljiljana Progovac ${ }^{\mathrm{c}}$ \\ ${ }^{a}$ Department of Spanish, Linguistics and Theory of Literature (Linguistics), Faculty of Philology, University of \\ Seville \\ ${ }^{\mathrm{b}}$ Department of Philosophy, Communication and Performing Arts. Roma Tre University \\ ${ }^{c}$ Department of English, Linguistics Program, Wayne State University
}

Received 3 November 2020; received in revised form 25 April 2021; accepted 26 April 2021

\begin{abstract}
As proposed for the emergence of modern languages, we argue that modern uses of languages (pragmatics) also evolved gradually in our species under the effects of human self-domestication, with three key aspects involved in a complex feedback loop: (a) a reduction in reactive aggression, (b) the sophistication of language structure (with emerging grammars initially facilitating the transition from physical aggression to verbal aggression); and (c) the potentiation of pragmatic principles governing conversation, including, but not limited to, turn-taking and inferential abilities. Our core hypothesis is that the reduction in reactive aggression, one of the key factors in self-domestication processes, enabled us to fully exploit our cognitive and interactional potential as applied to linguistic exchanges, and ultimately to evolve a specific form of communication governed by persuasive reciprocity - a trait of human conversation characterized by both competition and cooperation. In turn, both early crude forms of language, well suited for verbal aggression/insult, and later more sophisticated forms of language, well suited for persuasive reciprocity, significantly contributed to the resolution and reduction of (physical) aggression, thus having a return effect on the self-domestication processes. Supporting evidence for our proposal, as well as grounds for further testing, comes mainly from the consideration of cognitive disorders, which typically simultaneously present abnormal features of self-domestication (including aggressive behavior) and problems with pragmatics and social functioning. While various approaches to language evolution typically reduce it to a single factor, our approach considers language evolution as a multifactorial process, with each player acting upon the other, engaging in an intense mutually
\end{abstract}

Correspondence should be sent to Antonio Benítez-Burraco, Department of Spanish, Linguistics and Theory of Literature (Linguistics), Faculty of Philology, University of Seville, C/ Palos de la Frontera s/n, 41004 Seville, Spain.Email: abenitez8@us.es

This is an open access article under the terms of the Creative Commons Attribution License, which permits use, distribution and reproduction in any medium, provided the original work is properly cited. 
reinforcing feedback loop. Moreover, we see language evolution as a gradual process, continuous with the pre-linguistic cognitive abilities, which were engaged in a positive feedback loop with linguistic innovations, and where gene-culture co-evolution and cultural niche construction were the main driving forces.

Keywords: Language structure; Pragmatics; Self-domestication; Social behavior; Social cognition; Turn-taking

\section{Introduction}

Language is a hallmark of human cognition. How language evolved in our species has been an important concern for linguistics and cognitive sciences during the past decades. For the most part, research has been centered on the structural aspects of language and on the underlying computational abilities that enable us to put words together and construct (complex) sentences (and thoughts). Nonetheless, language is certainly a tool for interacting with others, and paying attention to language use is equally crucial for achieving a good understanding of how and why it evolved. As is the case with the computational abilities involved in sentence (dis)assembling, we should expect that our pragmatic abilities, that is, our knowledge of how language is put to use, also build on cognitive abilities and behaviors that exhibit continuity with other animals, although some human-specific innovations can be expected too. A thorough review of the evolution of the different abilities underlying pragmatics is beyond the scope of this paper, given that this process is expected to intersect with many, if not most of the changes which occurred during our speciation, from cognition to behavior to our body (see Levinson, 2016; Scott-Phillips, 2017 for useful references). Instead, we focus on a recent hypothesis about how our species emerged, namely, the self-domestication account of human evolution, which claims that human distinctiveness is to a large extent the outcome of an evolutionary process similar to animal domestication. We will examine whether, and to what extent, this fresh view can help us achieve a more comprehensive understanding of how pragmatics developed and changed over time.

In our previous research, we explored the effects of human self-domestication on the type of grammars putatively spoken by our species in our remote past (Benítez-Burraco \& Progovac, 2020; Progovac \& Benítez-Burraco, 2019). In this paper, we hypothesize that increased self-domestication also had a deep impact on language use, paving the way toward modern pragmatics. Specifically, we contend that the characteristic traits of human language use are strictly connected to the transition from a mostly unidirectional form of persuasive communication (inherent both in human and animal communication) to a form of communication governed by persuasive reciprocity. Stressing the role of competition as an equally important factor as cooperation, such transition characterized human communication in terms of conversation (Ferretti \& Adornetti, 2021; Ferretti, Adornetti, \& Chiera, submitted). In line with these considerations, we conceive the process of language evolution as an intense feedback loop involving multiple mutually engaged players, including (but not limited to) reduction in reactive aggression (linked to self-domestication), the gradual emergence and sophistication of grammar (also linked to self-domestication but impacting as well on self-domestication forces), and the gradual sophistication of pragmatics (which we will hypothesize to be linked 
to the other two players, impacting on them but being modeled by them as well), thus avoiding typical approaches to language evolution, which reduce it to a single factor. In addition, we consider that language evolution involves heavy reliance both on ancestral cognitive and behavioral strategies and on recent innovations. Finally, we regard gene-culture co-evolution and cultural niche construction as the main driving forces of this complex evolutionary process.

\section{The self-domestication approach to human evolution}

In comparison to extinct hominins and extant primates (perhaps with the exception of bonobos), humans exhibit an increased prosocial behavior. According to Hare (2017), selection for prosociality, and particularly for reduced in-group reactive aggression, might have played a crucial role in human evolution, impacting not only our behavior but also our cognition and most strikingly, our physical and physiological features. To be more precise, humans exhibit many of the biological and behavioral traits commonly found in domesticated varieties of mammals, compared to their wild conspecifics. These features include reduced cranial robusticity and brain size; reduced sexual dimorphism; neotenic traits, including a prolonged juvenile period, or a childish face; and changes in our behavior, including reduced reactive aggression and increased prosocial behavior, as noted, but also increased play behavior (Fukase, Kondo, \& Ishida, 2015; Herrmann, Hare, Cissewski, \& Tomasello, 2011; Leach, 2003; Plavcan, 2012; Shea, 1989; Somel et al., 2009; Stringer, 2016; Zollikofer \& Ponce de León, 2010). Because of this resemblance with domesticated animals, humans too have been hypothesized to have experienced a domestication process.

Nonetheless, while in mammals, domestication usually results from selection for tameness, as far as humans are concerned, several internal and external factors might have converged to trigger our domestication (or self-domestication), including changes in human foraging ecology; the rise of community living; co-parenting; and/or the deterioration of climate conditions during the Last Glaciation as harsh environments have been argued to favor prosocial behavior, specifically, intergroup tolerance (Spikins, French, John-Wood, \& Dytham, 2021); all of which seemingly resulted in a selection toward less emotionally reactive partners and toward tolerance for extra-group individuals (Hare, Wobber, \& Wrangham, 2012; Pisor \& Surbeck, 2019). Changes resulting from self-domestication have been claimed to account not just for the basic features highlighted above but also for many human-specific sophisticated traits, including our enhanced social cognition, increased cooperation, extended social networks, and ultimately our advanced technology and sophisticated culture (Hare, 2017). It has been hypothesized that the constellation of traits commonly found in domesticated varieties of animals, as also noted in humans, results from a common underlying physiological mechanism. According to this view, selection against aggression reduces the input to the neural crest, an embryonic structure that gives rise to many different body parts during development (Wilkins, Wrangham, \& Fitch, 2014).

It needs to be acknowledged that there is a lively debate around the ultimate origins of these purported features of domestication in humans and also of the very existence of a "domestication syndrome" resulting from the "tameness" of the neural crest. For instance, Lord, 
Larson, Coppinger, \& Karlsson (2020) have recently suggested that this "domestication syndrome" is undermined by a few key points, particularly by the fact that the presentation of its defining characteristics varies widely across species, to the extent that some of these features have not been observed in most domesticated species; some of the domestication traits could be characteristic of modern breeds but not an outcome of the domestication process itself; some/many features of domestication do not seem to co-occur with the onset of selection for tameness; and some domestication features, while being associated with tameness at the population level, might not correlate at the individual level so that they are not always exacerbated in the tamest animals (see Wright, Henriksen, \& Johnsson, 2020, for a defense of a "core" domestication syndrome). Sánchez-Villagra and van Schaik (2019) raise some cautionary notes about this syndrome too and also about the involvement of the neural crest in the emergence of features of domestication. Finally, Shilton, Breski, Dor, \& Jablonka (2020), in addition to pointing to some key differences between humans and other domesticated animals, support the view that selection for increased self-control and pro-social motivation (instead of reduced aggression) might be the leading force in the emergence of the purported features of domestication in humans. Overall, this is a pending issue that needs a more careful examination, but there is some consensus regarding the possibility that changes in behavior, either in self-control, or reactive aggression, or both, impacted upon our physiology and contributed to the changes we have highlighted above and also to the changes we will discuss in the rest of the paper.

Related to this, it has to be acknowledged as well that even if in-group tolerance and prosociality have increased with time in humans, intergroup, premeditated (i.e., proactive) aggression has increased recently in our history too (Choi \& Bowles, 2007; Wrangham, 2018). This trend contrasts with the behavior observed in our closest relatives; for example, bonobos do not engage in socially coordinated violence, whereas humans usually form relationships and alliances among groups, for example, making war (see Wrangham \& Glowacki, 2012, for discussion). Overall, we regard human self-domestication as a phenotype that can present in a variable fashion in humans depending on specific environmental factors. For instance, reduced sexual dimorphism (a core feature of domestication) is observed in societies where women have higher social status as a result of a sustained female preference for less-aggressive males (Gleeson \& Kushnick, 2018). Accordingly, as we discuss in more detail in the next section, we expect human self-domestication to have manifested as well in a variable fashion during our history, with features of domestication having increased over time but vacillating significantly depending on environmental factors. In this respect, candidate genes for animal domestication show signals of positive selection in anatomically modern humans, compared to Neanderthals (Theofanopoulou et al., 2017), favoring the view that increased self-domestication features may be a human-specific phenotype (see also footnote 1).

Still, this does not entail that a full self-domesticated phenotype was available in humans right after our inception, around $200 \mathrm{kya}$, as genomic comparisons have been made with present-day humans. Actually, research using ancient DNA suggests that a different set of candidates for mammal domestication has been positively selected in Europe as recently as 6 kya (Benítez-Burraco, Chekalin, Bruskin, Tatarinova, \& Morozova, in press), a period when profound social changes took place in this region, particularly the development of extensive 
trading networks and the spread of sedentism (Benítez-Burraco et al., in press). Likewise, craniofacial feminization reached its peak at the end of the Upper Paleolithic, when prehistoric hunter-gatherer societies flourished (Cieri, Churchill, Franciscus, Tan, \& Hare, 2014), pointing to a period when self-domestication features might have reached their peak too. Finally, there is evidence of our brains having been shrinking since around $40 \mathrm{kya}$, against the background of a generalized size increase in the hominin lineage (Bednarik, 2014), at times when intergroup contacts started to increase, this shrinking supporting the view that self-domestication may have intensified in recent times.

Overall, it is true that the self-domestication hypothesis of human evolution needs to be more carefully examined and properly tested in all its details. But at the same time, although it is difficult to suggest a precise timeline for our self-domestication, we contend that it can be quite safely accepted that reactive aggression (i.e., impulsive, non-premeditated aggression resulting from fear or anger) has declined over the course of our history, this certainly contributing to changes in our biology and behavior through changes impacting upon our physiology. For these reasons, in the rest of the paper, we will use self-domestication as a shorthand for all the changes associated with the changes in aggression management.

\section{Human self-domestication and language evolution}

The finding that domestication triggers song complexity in some avian species (see Okanoya, 2017 for review) has led to the hypothesis that self-domestication might have contributed to the emergence of complex forms of language in our species too (Thomas \& Kirby, 2018). Whereas in birds, song complexity seemingly results from the relaxed selection encompassing the domestication environment, in humans, the self-domestication environment has been specifically claimed to account for the cultural niche that enables the sophistication of language via a cultural mechanism (Benítez-Burraco \& Progovac, 2020; Thomas \& Kirby, 2018; see Steels, 2017; Tamariz \& Kirby, 2016, for the effects of cultural evolution on language complexity). A cultural niche refers to cultural features aimed to reduce or redirect the impact of the selective pressures that individuals experience (Laland et al., 2000). Cultural niche construction has been hypothesized to have contributed not only to the emergence of our modern languages but also, more generally, to our species-specific propensity for learning and using languages (Sinha, 2015), as well as many other distinctive features of the human phenotype (Kobayashi, Wakano, \& Ohtsuki, 2019; Laland et al., 2000).

Our abilities for cultural niche constructing are likely rooted in our species-specific biology, particularly our distinctive cognition and behavior, given that we learn the basics of our culture through practices that demand specific attentional, behavioral, and cognitive abilities, such as the capacity for inferring others' expectations and behaviors (e.g., theory of mind (ToM); see e.g., Dressler, 2020; Sections 8 and 9). This is why we find it intriguing that the possibility of the biological changes that resulted in the appearance of our species also brought about the foundations for the abilities that facilitated the creation of our cultural niche, particularly the environment that favors the sophistication of languages. Actually, as stressed by Smith (2011), the way in which human languages evolve through a cultural 
mechanism depends on the biological biases imposed on our language learning abilities. At the same time, there is evidence of a differential impact of the languages that we learn and use on selected cognitive abilities, such as working memory (Amici et al., 2019), and eventually on our cognitive architecture, particularly if cognitive gadgets aimed to process them more quickly and efficiently are implemented (Clarke \& Heyes, 2017). Consequently, we can expect some sort of gene-culture co-evolution concerning the emergence of complex languages under the effects of self-domestication via its effects on cultural niche construction.

For instance, as noted in the previous section, in our research, we have found preliminary evidence that there has been selection for putative candidate genes for human selfdomestication during the last 6,000 years in Europe (Benítez-Burraco et al., in press). As also noted, this is a period when important social and cultural changes occurred, including the spread of sedentism, the increase in population density, and the development of complex trading networks, all of them seemingly impacting in-group and inter-group human interactions. At the same time, this is the period when Neolithic languages were almost totally replaced by Indo-European languages (Bouckaert et al., 2012; de Barros et al., 2018; Mathieson, 2018, among many others). Interestingly, during this period, evidence has been found as well of selection in genes coding for components of pathways related to long-term potentiation, which underlies synaptic plasticity and ultimately memory and learning abilities (Chekalin et al., 2019). As these changes can be safely related to changes in ways of information presentation, perception, and transmission, one could hypothesize that their ultimate driving force was the transition to more memory-demanding languages, in this case, Indo-European languages, as they contrast with Neolithic languages.

Different mechanisms involved in the cultural evolution of languages might have been reinforced by self-domestication, including grammaticalization (Benítez-Burraco, 2017a), language learning and teaching (Benítez-Burraco \& Kempe, 2018), and language play (Langley, Benítez-Burraco, \& Kempe, 2019). It is clear, however, that the most important consequence of self-domestication would have been the reduction in reactive aggression, which underlies most of the afore-mentioned mechanisms, as it enabled longer and more frequent contacts between individuals, including contacts with out-group individuals in the case of adults and contacts with larger networks of caregivers in the case of children.

In two recent papers (Benítez-Burraco \& Progovac, 2020; Progovac \& Benítez-Burraco, 2019), we have argued for an intense feedback loop between self-domestication processes and grammar complexity. Briefly summarizing our hypothesis, early in evolution, this loop concerned reactive aggression. According to our proposal, a gradual reduction in reactive aggression started to facilitate the emergence of early forms of grammar, as it enabled more frequent and longer contacts between individuals, and accordingly more learning and teaching opportunities and ultimately an increase in language complexity via a cultural mechanism. In turn, the cultural emergence of early grammars itself had a crucial return role to play in this feedback loop, by reinforcing and accelerating self-domestication processes and thus contributing even more to the reduction of reactive aggression. Our specific proposal is that this impact of early grammars on self-domestication was primarily due to their role in supporting creative and colorful derogatory language, thus providing a means for replacing physical aggression with verbal aggression. In addition, the humorous nature of this type of 
early language would have also provided some stress relief, another important trait of selfdomestication. In other words, the postulated early forms of language/grammar would have provided an excellent adaptive means of discharging aggressive dispositions and for competing without risking physical harm (Progovac \& Locke, 2009). In Progovac and BenítezBurraco (2019) we argued that reactive aggression and verbal derogatory language share a common neural substrate; there are many additional points of contact between the two that allow some specific hypotheses to be advanced.

Furthermore, consistent with the idea of the feedback loop, these early grammars became more complex and systematic as in-group and inter-group interactions intensified as a result of exacerbated self-domestication in our species, particularly reduced reactive aggression. In our view, when self-domestication reached a significant height, around 50 kya, the low reactive aggression together with its effects on human behavior and even cognition (emergence of tight and dense in-group networks; prolonged, face-to-face verbal interactions; in-group knowledge sharing; increased child-adult contacts; extended play behavior) facilitated the creation of the first hierarchical grammars expressing, for example, transitivity, in other words, the type of grammars associated with the so-called esoteric languages (Wray \& Grace, 2007). In comparison to the so-called exoteric languages, which are considered to have emerged later (see below), esoteric languages can be characterized as exhibiting more complexity in certain domains (phonology, phonotactics, morphology), but less complexity and systematicity in other domains (e.g., syntax), often featuring irregular morphologies (with more irregularities and morpho-phonological constraints) and less transparent, less compositional semantics (with an abundance of idiomatic and idiosyncratic expressions); see Benítez-Burraco \& Progovac, 2020, for a more detailed discussion. These distinctive features of esoteric languages seem to correlate with (a) their greater reliance on the common ground, (b) smaller population sizes, and (c) the acquisition of these languages mostly by young children rather than by adult learners (see e.g., Lupyan \& Dale, 2010; Raviv, Meyer, \& Lev-Ari, 2019, 2020).

Later in evolution, we argue that this feedback loop concerned proactive (i.e., premeditated) aggression (Benítez-Burraco \& Progovac, 2020), with increased proactive aggression correlating with the emergence of other complex forms of language, more systematic, and better designed for interacting with non-kin, including escalated conflicts and alliances. As noted by Kissel and Kim (2019), large-scale proactive conflicts usually entail conscious forethought, premeditated planning, and ultimately cultural institutions around war and peace, all of this, in turn, demanding complex cognition and enhanced language precision. This new type of language has been called "exoteric" (Wray \& Grace, 2007). In contrast to esoteric languages, exoteric languages feature expanded vocabularies and increased syntactic complexity and semantic transparency (including greater reliance on recursion) but simpler sound combinations and phonotactics, as well as simpler, more systematic morphologies (see Benítez-Burraco \& Progovac, 2020, for a more detailed characterization).

Overall, we have posited a gradual model of the evolution of human languages under the effects of self-domestication, from simple (even single-word) utterances (such as commands) to simple two-slot grammars (such as compounds and small clauses) to present-day grammars, capable of generating complex multilayered sentences. Our proposal regarding gene-culture co-evolution is very specific. It involves genetic selection for less aggressive 
phenotypes, not just phenotypes that were tame and mute (in the sense of inarticulate) as bonobos are, but more specifically phenotypes that were better able to replace physical with verbal aggression and verbal behavior more generally; that is, those who were better able to make adaptive use of the newly emerging cultural tools (Progovac \& Benítez-Burraco, 2019). This is where the taming of physical aggression (associated with genetic changes) meets the emergence of simple forms of language/grammar (associated with the cultural invention), getting them entangled in a gene-culture co-evolutionary spiral. In this paper, we will show how this gradual model of the origins of human languages, and more precisely, this feedback loop, is closely connected to the actual use of language in conversation too, giving rise to a virtuous cycle of co-evolution between grammar, pragmatics, and self-domestication. As with the evolution of the structural properties of language, our model of pragmatics evolution brings cultural niche construction and gene-culture co-evolution to the forefront.

As a note of clarification, we are not claiming that self-domestication was the only force promoting the emergence of modern languages or that self-domestication actually caused the emergence of language. Otherwise, one could argue that any primate species experiencing a self-domestication process (e.g., bonobos) should have developed a complex language. Instead, we have proposed that this trend toward reduced reactive aggression merely brought about the suitable environment (cognitive perhaps, but mostly behavioral and cultural) for putting to use some cognitive and behavioral human-specific innovations, such as the cultural emergence of simple forms of language. In other words, the idea of the mutually reinforcing feedback loop is that two or more independently emerging phenomena get intensely entangled with each other in such a way that they start to reinforce and accelerate each other's evolution; that is our basic claim about the feedback loop between self-domestication processes and the emergence of simple forms and uses of language. As there is nothing inevitable about evolving a certain trait, especially not a trait as baroque and bizarre (from the point of view of nature) as is human language, we contend that, even if the prerequisites existed, the likelihood of evolving such a trait was minuscule. Our approach is well-positioned to address this issue by identifying two or three factors that arguably happened to have been emerging independently, and then collided at exactly the right moment, and in such a way that they significantly and intensely reinforced each other. If so, then there is no reason to expect that such exceptional, chance convergence would be replicated with other species and at other times.

\section{Human self-domestication and pragmatics}

O'Driscoll (1996) has noted that any theory of politeness (and pragmatics more generally, we would like to add) needs to build on psychosocial principles of animal interaction (coming together vs. noli-me-tangere), in which the aggression types and levels play a key role. Because, as noted, the management of aggression is at the core of the self-domestication hypothesis, we contend that this approach to human evolution can also be informative regarding the evolution of human pragmatics. As seems to be the case with the emergence of modern grammars, we propose that modern uses of languages (pragmatics) might have also evolved gradually in our species under the effects of human self-domestication, with three key aspects 
involved in a complex feedback loop: (a) reduction in reactive aggression; (b) the sophistication of grammar structure (with emerging grammars facilitating the transition from physical aggression to verbal aggression, as discussed above); and (c) the potentiation of pragmatic principles governing conversation, including, but not limited to, turn-taking and conversational implicature, associated with Gricean cooperative principle (Grice, 1975) as well as maxims of politeness (Leech, 1983). Regarding this feedback loop, we wish to introduce two important qualifications. First, arguing for an ongoing, late emergence of the full human capacity for pragmatics is still compatible with the view that it relies on basic cognitive and behavioral mechanisms that are ancient, particularly the foundations of principles governing conversational exchange (Hoefler \& Smith, 2009; Levinson, 2016). Second, although our focus in this paper is placed on the last aspect (c), that is, the emergence of pragmatic principles, these principles are expected to interact with the other two aspects, that is, (a) and (b), in multiple and complex ways.

On the one hand, as hypothesized for the increasingly sophisticated forms of grammar (see Progovac \& Benítez-Burraco, 2019), the increasingly sophisticated uses of language are expected to have contributed to reduced reactive aggression levels, as they facilitated the replacement of physical aggression by verbal contests. On the other hand, sophisticated pragmatic inferencing, that is, the ability to create and understand the implicit meanings conveyed by utterances, is expected to have contributed significantly to grammar sophistication, given its crucial role in grammaticalization processes (Hopper \& Traugott, 2003: pp. 71-98; Smith \& Höfler, 2014). Grammaticalization changes certain linguistic items into more abstract and regular grammar components (Campbell \& Janda, 2001; Givón, 1979; Hopper \& Traugott, 2003) and has been claimed to contribute considerably to the emergence of modern languages (see Heine \& Kuteva, 2007 for a detailed discussion). In a similar vein, Pleyer (2017) has recently advocated a dynamic view of grammar evolution based on the emergence of constructions in ongoing interaction. At the same time, the gradual complexification of grammars certainly provided increasingly better expressive tools for further sophistication of pragmatic principles, contributing to the mutually reinforcing feedback loop. For example, it has been suggested that important abilities for the use of language in conversational contexts, such as the ToM and perspective-taking (more on this in Sections 8 and 9), are enhanced by the acquisition of grammatically sophisticated linguistic structures (e.g., De Villiers, 2005; Heyes \& Frith, 2014; Milligan, Astington, \& Dack, 2007; Moore, 2020; Rakhlin \& Progovac, 2020; Woensdregt, Cummins, \& Smith, 2020).

Specifically, our hypothesis is that self-domestication contributed to the emergence of modern pragmatics in two different but still complementary ways: by promoting changes in our cognition and social behavior.

\section{Human self-domestication and pragmatics: The impact on cognition}

First, self-domestication can be seen as a mechanism promoting direct changes in our brain/cognition favoring the evolution of the pragmatic principles that govern language use and the abilities that are needed for a successful language interaction. Because the brains of 
domesticated animals have been shown to reorganize adaptively in response to the domestic environment (e.g., Kruska, 1988, 2005), we can expect that human brains also readapted to the self-domestication environment. Specifically, as a result of its primary impact on the management of aggression, self-domestication might have contributed significantly to the (full) emergence of our social brain. According to some views, this involved the generalization of pair-bonds to other non-reproductive relationships (Dunbar, 2009), and ultimately a modification of ancestral brain systems characterized by non-social or more limited social functions (Parkinson \& Wheatley, 2015), where increasingly complex social interactions and social networks played a leading role in this change (Falk \& Bassett, 2017), with all these aspects being potentiated by the reduced reactive aggression levels brought about by our increased self-domestication. Self-domestication would have also favored the evolutionary trend toward social dependency for survival, in turn, a driving force for a socially crafted brain development and learning, which also entailed the reorganization and remodeling of various preexisting neural systems (see Atzil, Gao, Fradkin, \& Barrett, 2018, for details).

In addition, our enhanced self-domestication would have favored as well the (full) emergence of cognitive abilities that are not directly implicated in our social behavior but that are also crucial for pragmatics. The most important one was, certainly, our ability to put into relation conceptual units that belong to distinct domains, a hallmark of human cognition (Boeckx, 2011; Carruthers, 2006; Mithen, 1996; Spelke, 2003; Wynn \& Coolidge, 2011). This ability is central to the figurative uses of language, such as metaphors and metonyms, and particularly to pragmatic inferencing. According to Corballis (2019a, 2019b), it can be viewed as an enhanced generative device that boils down to our refined episodic memory (EM), which enables us to mental travel both forward and backward in time, and it underlies one human-specific cognitive device that is crucially involved in pragmatics, namely, our mental time travel (MTT) system (see Section 8 for a more detailed discussion). According to Corballis, our MTT ability has been improved by selected changes in the hippocampus. In addition to its contribution to EM (Andelman, Hoofien, Goldberg, Aizenstein, \& Neufeld, 2010; Corballis, 2017; Maguire, Intraub, \& Mullally, 2016), the hippocampus is also involved in spatial navigation and cognition (Maguire et al., 1998; Vinogradova, 2001) as well as in stress management (McEwen et al., 2012). Interestingly, domestication usually results in hippocampal modifications. Accordingly, the hippocampus of domesticated animals is larger, compared to their wild conspecifics (Rehkämper et al., 2008) and exhibits increased neurogenesis (Huang et al., 2015). Given that a significant portion of the evolutionary changes experienced by the human brain affected the hippocampus (Schilder et al., 2019; Vanier et al., 2019; Xu et al., 2018), it could be hypothesized that our self-domestication contributed to the hippocampal changes important for our cognitive evolution via aggression management (see Benítez-Burraco, 2021, for details). In the last part of our paper, we advance a model of pragmatics evolution under the effects of self-domestication in which the changes in the hippocampus and the MTT system play an important role (see specifically, Section 9).

Overall, these considerations suggest that the cognitive hardware supporting our ability for sophisticated pragmatic inferencing emerged gradually, being constantly refined by our increased self-domestication, as well as by the sophistication of grammars, which would 
imply that this ability appeared in our history later than previously assumed (see BenítezBurraco, 2017a for further discussion). But even if our cognitive hardware, including a socialand a language-ready brain, was available earlier, right after, or soon after the advent of our species, the social environment would not have favored its full realization, as the high levels of reactive aggression would have prevented long and frequent interactions between individuals that characterize modern uses of language. This is why we regard the impact of self-domestication on our behavior as of particular relevance for the evolution of modern pragmatics.

\section{Human self-domestication and pragmatics: The impact on behavior}

For the reasons provided above, the most important effect of self-domestication on the evolution of pragmatics may have been promoting direct changes in our behavior and reinforcing aspects of our ancestral behavioral phenotype that favored the evolution of the pragmatic principles that govern language use and the abilities that are needed for a successful language interaction. In other words, self-domestication might have contributed decisively to the emergence of the social environment that enabled the full exploitation of our cognitive abilities. Moreover, because in humans, complex cognitive abilities may be fruits rather than seeds of cultural selection, as noted by Heyes (2020), we expect that these changes in our social environment resulting from self-domestication had a feedback effect on our cognitive architecture, involving some sort of gene-culture co-evolution. To some extent, this can be found in other species. For instance, in animals, domestication results in an enhanced sensibility to human social cues as well as an improved ability to solve problems relying on social cues (Hernádi, Kis, Turcsán, \& Topál, 2012; Udell, 2015). The same can be expected for our species but to a greater extent.

More specifically, we contend that a higher degree of reactiveness, as found in nonself-domesticated primates, would have adversely affected fine-tuned turn-taking, which demands prolonged face-to-face interactions, as well as a high degree of cooperation and sensitivity to the needs of one's interlocutors, which are at the basis of the modern use of language (e.g., Levinson, 2016; Wacewicz, Żywiczyński, \& Chiera, 2017). It transpires that self-domestication forces, which led to the decrease in reactive aggression and longer and richer interactions, were essential contributors to this kind of sophisticated turn-taking.

Levinson (2016) believes that turn-taking has deeper roots, considering that, in contrast to the diversity of languages, turn-taking seems to exhibit strong universality. He sees turntaking as a package of underlying propensities in human communication, which "generate a large number of universals of language use, including principles of pragmatic inference" (p. 10). Nonetheless, present-day turn-taking is rapid and complex, and thus cognitively highly demanding, as it needs to accommodate two conflicting pressures: the pressure to minimize gaps between turns and avoid overlaps (see e.g., Levinson, 2016, or Wacewicz et al., 2017). Our view is that our enhanced self-domestication significantly contributed to enabling the full use of this ancient package (more on this in Section 8 below). 
From this point of view, it is not surprising that vocal turn-taking has also been attested in other species; for example, birds and other primates, and according to Pika, Wilkinson, Kendrick, \& Vernes (2018), cooperative turn-taking can be seen as an ancient mechanism bridging the gap between humans and their inarticulate primate cousins (see also Levinson, 2016; Wacewicz et al., 2017). Bearing in mind the role of conversation in accounting for the origin of pragmatics in a context of self-domestication, the idea that turn-taking characterizes animal - other than human-communication paves the way toward several interesting issues to be addressed. The first is an evolutionary issue: Arguing that turn-taking is a universal trait of human communication is a way of considering it a species-specific adaptation that can be interpreted both in reference to a common phylogenetic history with our closest relatives (Sidnell, 2001) and in terms of functional convergence in species that are phylogenetically distant from us (Hausberger, Henry, Testé, \& Barbu, 2008). In line with Henry, Craig, Lemasson, \& Hausberger (2015), considering turn-taking in terms of functional convergence allows us to take into consideration animals such as birds and thus consider turn-taking as a widespread phenomenon in animal communication. A second important issue concerns the possibility to consider as "conversation" any form of animal communication characterized by turn-taking. This is a point of great interest since, as already mentioned and as we will see in depth in Section 8 , our hypothesis is that conversation is characterized by traits specifically linked to persuasive reciprocity, a property at the heart of human communication, for which both specific cognitive skills (see Section 8.3) and a language with a more systematically structured grammar (see Section 8.4) are needed. Recognizing turn-taking in non-human animals is not enough, in our opinion, to attribute conversational features to their forms of communication. That said, the comparison with non-human animals is of great importance when investigating the elements of commonality and difference between the different forms of communication.

\section{Human self-domestication and pragmatics: A general model}

As a result of these two effects of self-domestication (i.e., cognitive and behavioral changes impacting on the social settings), it can be hypothesized that face-to-face interactions became more frequent and richer, with richer inferences and with more complex meanings starting to be conveyed by more indirect means. Some corroborating evidence for this view may come from the languages spoken by present-day isolated human groups. As introduced in Section 3, these languages are mostly characterized by an abundance of idioms and idiosyncratic speech, resulting in reduced semantic transparency, thus showing greater reliance on the context of the here-and-now, as well as on the shared knowledge, demanding enhanced inferring abilities. Such language features can be considered as rough proxies of the languages spoken during the Upper Paleolithic (see e.g., the discussion in Benítez-Burraco \& Progovac, 2020), and it is significant that the effects of self-domestication reached their peak in the Upper Paleolithic (Cieri et al., 2014). At the same time, the aforementioned changes in our brains, cognitive abilities, and behavior, to a large extent facilitated by our self-domestication (but also stimulating it), can be expected to have resulted in the complexification of grammar too. The languages spoken by present-day isolated human groups as well show ample 
evidence of language complexification, including larger phoneme inventories and more complex phonotactics as well as complex, irregular morphologies, although co-occurring with reduced semantic transparency, as noted, and with more basic hierarchical syntaxes, seemingly because of their greater reliance on the common ground shared by speakers, in turn, a consequence of the tight social bonds brought about by increased self-domestication. Ultimately, consistent with the postulated feedback loop, the emergence of more structured and complex expressive resources of grammar would have made communicative exchanges more effective, impacting positively on our pragmatic abilities. We now provide a more detailed justification of these claims and a more elaborated model of the effects of self-domestication on the evolution of human pragmatics, in which conversation plays a key catalyst role.

\section{Human self-domestication and pragmatics: A detailed model}

Some preliminary considerations are required of a model of language capable of addressing the role of self-domestication in the intertwined relations between cognition, pragmatics, and grammar. Our hypothesis is that the reduction in reactive aggression is at the foundation of a form of communication-based on conversational exchanges characterized by persuasive reciprocity. The first step to justify this hypothesis is the reference to a specific way of intending communication, which emphasizes that communicating primarily serves to convince others to think and act in a certain way. Contrary to the idea of communication as merely transmission of information (Shannon \& Weaver, 1949; for a current revival: Bradbury \& Vehrencamp, 1998; Greenfield, 2002; Hauser, 1996; Seyfarth et al., 2010), our assumption in this paper is that human communication (but also animal communication) is mainly a tool of persuasion. As maintained by proponents of the manipulative model of communication (Dawkins \& Krebs, 1978; Krebs \& Dawkins, 1984; Maynard Smith \& Harper, 2003; Owren, Rendall, \& Ryan, 2010), "communication is said to occur when an animal, the actor, does something which appears to be the result of selection to influence the sense organs of another animal, the reactor, so that the reactor's behavior changes to the advantage of the actor" (Dawkins and Kreb, 1978 p. 283; for an analysis of the receiver manipulation of the sender, cf. Beecher, 2021). In this model, the persuasive role of communication is commonly aimed at coping with the aggressive behavior of the aggressors toward the victims (Hawhee, 2011, 2017; Kennedy, 1992, 1998; Parrish, 2013, 2014). Consequently, given that the essential outcome of human self-domestication is the reduction of aggression toward others, self-domestication can be expected to have contributed to the potentiation of the communicative and persuasive strategies. In turn, these strategies, further facilitated by emerging grammars, are expected to have contributed to the escalation of our self-domestication (see Progovac \& Benítez-Burraco, 2019 for details regarding this feedback loop).

Certainly, conflict avoidance strategies described by the manipulative models of animal communication do not require the use of language as we find it in humans, thus proving to be too weak to account for the totality of human communication. Among animals, in fact, attempts by the victim to convince the aggressor have a unidirectional character, whereas in humans, the distinctive feature of communication is persuasive reciprocity. Animal 
communicative exchanges based on manipulative persuasion can then be conceived of as forms of proto-conversation, with the transition to full conversational exchanges, as found in humans, involving the emergence of a two-way mechanism in which actors and reactors continuously exchange roles in a form of persuasive reciprocity. In this respect, with their limited back and forth, simple exchanges of insult relying on proto-grammars (as discussed above) can be seen as straddling the boundary between primarily unidirectional systems and fully reciprocal systems.

\subsection{Communication and argumentation}

The idea that conversation is characterized by persuasive reciprocity has important consequences on how to consider human communication. In conversation, in fact, beyond the aim of making herself understood by her interlocutor, the communicator aims at making the interlocutor accept to believe and do what she expects her to believe and do (Sperber et al., 2010). The issue of acceptance complicates the communicative effectiveness of the communicator because the addressee, in addition to putting trust in the speaker, is also animated by a state of vigilance and defense against possible cheating. Trust and suspicion, as we shall now see, are not in conflict with each other but are part of a unitary cognitive processing.

The idea that communication is based on a truthful use of language has solid foundations in theoretical reflection (Burge, 1993; Davidson, 1984; Lewis, 1969) and empirical research (Gilbert, Krull, \& Malone, 1990; Gilbert, Tafarodi, \& Maloine, 1993). Wacewicz and Żywiczyński (2018) consider human communication to be founded on the platform of trust (PoT; Knight, 1998, Wacewicz, 2015): a deep design feature of language, based on a form of "information donation" characterizing humans able to flip "the default setting from expecting manipulation to expecting honesty" (Wacewicz \& Żywiczyński, 2018, p. 170). In this perspective, framing human communication in reference to PoT is a way to stress the cooperative and altruistic aspects of communication (Tomasello, 2008).

That said, trust involves risks: Lying and untruth can be used by the communicator to deceive the addressee. This undermines the addressee's confidence toward the speaker. Sperber et. al (2010; Mercier, 2020; Mercier \& Sperber, 2017) described the defense strategies used by the addressee to defend herself against cheaters in terms of epistemic vigilance (an adaptive defense strategy, which primarily involves the resistance of the addressee to accept what is communicated to her). For the communicator, the addressee's vigilant attitude is an obstacle that can be overcome using persuasive strategies. According to Mercier and Sperber (2009; Sperber, 2001; Sperber et al., 2010), reasoning is a communicative tool whose main function "is to enable communicators to produce arguments designed to convince others and addressees to evaluate arguments so as to be convinced only when appropriate" (Sperber et al., 2010, pp. 377-378). At the basis of the argumentative theory of reasoning is the idea that reasoning is a cognitive capacity strictly connected to the social and communicative context. Even if reasoning can work at an individual level, in fact, "reasoning in non-communicative context is an extension of a basic component of the capacity for epistemic vigilance towards communicated information" (Sperber et al., 2010, p. 379). To this extent, the function of argumentation is linked to communication rather than to individual cognition since reasoning "is 
an evaluation and persuasion mechanism, not, or at least not directly, a knowledge production mechanism" (Sperber, 2001, p. 410).

Acknowledging the vigilance strategies used by the addressee and the argumentative strategies for persuasive purposes used by the communicator is a way to challenge the "altruistic" model of communication based on the PoT. This represents a crucial theoretical statement that highlights the role of self-domestication in the evolution of a form of communication governed by the principle of persuasive reciprocity and, at the same time, the effect of persuasive reciprocity on self-domestication. This can be considered a virtuous circle: On the one hand, self-domestication, favoring face-to-face interactions, worked as a selective pressure toward forms of communication governed by strategies of persuasive reciprocity; on the other hand, these strategies represented the primary condition for reducing aggression, which, as we have emphasized, is the main feature of self-domestication. In the first part of this paper, we have considered the role played by self-domestication in favoring typically human forms of communication; here, we intend to stress the return effect of conversation on self-domestication. Since the relationship between self-domestication and the origin of pragmatics hinges on this point, our main interest in the following sections will be the analysis of the role of conversational strategies in reducing reactive aggression. Specifically, we intend to investigate the effect of conversation on self-domestication through the study of an aspect particularly relevant for our purposes: The fact that in communicative exchanges governed by persuasive reciprocity, the reduction of reactive aggression is closely tied to the replacement of physical aggression with (proactive forms of) verbal contest. As we will see in the next paragraph, reduction and replacement are closely connected to each other and strongly linked to one of the distinctive traits of human conversational exchanges: their competitive as well as cooperative character.

\subsection{Conversation and competition}

By considering the listener's epistemic vigilance and the speaker's persuasive strategies, we do not intend to question the role of cooperation in communicative exchanges. Rather, we attempt to undermine the idea that cooperation and trust in the interlocutor are sufficient conditions to account for conversational exchanges. In line with the proponents of the "strategic pragmatic," we contend that Grice's cooperation principle is unable to explain forms of conversation in which the agents' motives do not align (Asher \& Lascarides, 2013; Lascarides $\&$ Asher, 2008). Senft (2018) criticized the universal character of Gricean maxims; Pinker, Nowak, and Lee (2008) used the logic of indirect speech to argue that if one looks at communication only in cooperative terms, then one fails to recognize "that most social relationships involve combinations of cooperation and conflict" (Pinker et al., 2008, p. 833). Similar considerations led Reboul (2017) to criticize altruistic models of communication, using the argumentative theory of reason to propose a model (mildly Machiavellian or manipulative) in which language allows individuals to persuade others so that their own opinions should prevail over opposite opinions.

Following these considerations, we contend that looking at human communication in reference to cooperation alone risks overshadowing the competitive dynamics that represent the 
specific feature of conversational exchanges in terms of persuasive reciprocity. Competition is what gives human communication a progressive and cumulative character, without which conversation "runs in circles" and does not go forward (as we will see looking at the case of autism). To push communication forward is the contrast between interlocutors: During a conversation, the addressee is not only vigilant with respect to the truth and coherence of what the speaker says but also retorts and counter-argues in favor of her own point of view. It should be emphasized that the competitive nature of communication also marks a point of distinction with respect to the argumentative theory of reason proposed by Sperber et al. Indeed, their model is still strongly linked to cooperation and trust, albeit an undersurveillance trust - epistemic vigilance in fact "is not the opposite of trust; it is the opposite of blind trust" (Sperber et al., 2010, p. 363). Trust and cooperation are no doubt constitutive traits of communication, and the defense against false information is a decisive technique for the success of conversational exchanges. That said, the discussion between trust and distrust does not exhaust the traits characterizing human communication. The strategy of reciprocal persuasion between speaker and listener goes beyond the need of circumventing the interlocutor's epistemic vigilance: Communication, in other words, is above all a strategy to propose a specific point of view and to defend that point of view with respect to the counterarguments of the interlocutors (Ferretti \& Adornetti, 2021). Human beings participate in communication from a specific perspective, proposing alternative worldviews, and conversation is the continuous game of arguing and counterarguing between communicator and addressee in defense of their own opinions. These considerations lead us to consider in more detail the pragmatics of conversational exchanges based on persuasive reciprocity. In actual contexts of use, indeed, communication rests on the constant interchange of roles between speaker and listener.

The continuous exchange of roles between actors and reactors enhances the constructive character of human conversation. Even when the speakers defend opposite points of view, the conversational exchange never leaves the interlocutors at the point from which they started: Conversation lends to communication a directional, progressive, and cumulative character (Adornetti, 2015; Ferretti \& Adornetti, 2012, 2021; Ferretti et al., submitted). Fusaroli, Rączaszek-Leonardi, and Tylén (2014) considered dialogue as a dynamical system governed by the complementary roles of interlocutors. In line with this approach, conversation analysis (Sacks, Schegloff, \& Jefferson, 1974; Schegloff, 1997; Sidnell, 2011) represents an interpretative paradigm particularly useful for evaluating the constructive character of communication. In Perkins' (2007) opinion, such interpretative paradigm "views conversations as being co-constructed between participants and examines the significance of sequential phenomena, and the way in which participants orient to each other and manage the interaction generally (Atkinson and Heritage, 1984); rather than simply taking account of and reacting to context, conversation is also seen as continuously shaping and renewing the context" (p. 27).

Conversation is the means by which humans have reduced physical violence since conversation is a way to transform physical contrast into a verbal disagreement. This is a crucial step for the analysis of the role of conversation in reducing reactive aggression. Conversation combines the two aspects (reduction and replacement of aggression) characterizing the role of language in self-domestication. In conversation, in fact, the verbal contrast (the competitive 
character of human communication) is hardly ever an end in itself: The purpose of conversation is always, at least in principle, agreement and cooperation between interlocutors. Because of the cumulative and progressive trait of conversational exchanges, the ultimate function of conversation is the resolution of conflict. Indeed, arguing and counter-arguing by the interlocutors (their disagreement) have as their goal the convergence of opinions or the recognition of the prevalence of an argument over the other. From this point of view, the reduction of reactive aggression through conversation is strictly connected with the replacing of physical aggression with verbal disagreement. Recall that a similar argument was made for the evolution of early, crude forms of language, which proved to be especially suited for insult and also served to replace reactive physical aggression with verbal aggression, but in a much more rudimentary, primitive fashion (Progovac \& Benítez-Burraco, 2019, and references there). If one of the main traits of self-domestication is the reduction in reactive aggression, then present-day human languages (and modern uses of language) can be considered at the same time the outcome and the condition for self-domestication. That said, two further steps are needed to consider the role played by conversation in the origin of human language. The first step concerns the structural conditions (the cognitive devices necessary to process conversational communication), while the second one regards the material conditions (the construction of a complex expressive code suitable for conversational communication).

Recalling our discussion above (Sections 5 and 6), our contention is that moving from the unidirectional proto-conversational forms of conflict avoidance to the forms of persuasive reciprocity characterizing human conversation, with a conversational context based on giving reasons and replying to the interlocutor, might have entailed a two-step evolutionary process, with the first step mainly guided by our cognitive architecture, and the second step largely relying on the emergence of a progressively more complex and structured expressive system. These two developments would have been engaged in a mutually reinforcing feedback loop, and both would have been facilitated by our self-domestication.

\subsection{Cognitive architectures}

Regarding the first step, it should be noted that in the early stages of human communication, in the absence of a rich, structured expressive system, the burden of conversational communication must have fallen almost entirely on non-linguistic aspects of our cognitive systems. Still, "far from being 'easy' as some psychologists have suggested, conversation may be one of the most demanding cognitive tasks in everyday lives" (Holler, Casillas, Kendrick, \& Levinson, 2016, p. 2). This means that modern conversational exchanges likely demanded some sort of cognitive adaptation, as explicated below in the context of processing speed, as well as certain novel (or at least, improved) cognitive devices, including those associated with the ToM and MTT (Section 5). Following the proponents of the cultural view of cognitive evolution (e.g., Heyes, 2018), we contend that these cognitive modifications mostly resulted from the changes in our social and cultural environment, in our view from the changes brought about by our self-domestication, eventually entailing some form of gene-culture co-evolution involving language. 
Here, we focus on the cognitive systems involved in persuasive reciprocity only, but the same evolutionary model can be applied, we contend, to other cognitive devices involved in modern language use. Focusing on persuasive reciprocity, conversational exchanges rely on two particularly important strategies: topic preservation (i.e., the ability to maintain the arguments in favor of one's point of view but also to integrate them with new information) and topic shift (i.e., the ability to change one's arguments in order to explore new, more effective, argumentative strategies; Sng, Carter, \& Stephenson, 2018). Both strategies are intimately connected to turn-taking, which, as noted above (Section 5), is one of the cornerstones of conversation (see also Holler et al. 2016; Levinson, 2016; Sacks, 2014). Although, as also noted, turn-taking can take place also in the absence of conversation, as in nonhuman animal communication (Henry et al., 2015; Pika et al., 2018), it is only in the conversational context, in fact, that turn-taking becomes an expression of the exchange of roles between actor and reactor generated by the continuous alternation of points of view underlying their persuasive reciprocity.

The study of the cognitive devices involved in topic preservation/shift and turn-taking during conversational exchanges illuminates the nature of the changes and innovations involved in the evolution of modern pragmatics, under the effects of self-domestication, as we wish to add. Turn-taking entails several cognitive challenges. The fast processing speed of turn-taking (with response times of approximately $200 \mathrm{~ms}$ in all languages, according to Levinson, 2016) comes in contrast to the relatively slow time of linguistic processing (with response times of 600-1000 ms for words and about 1500 for short clauses). As a consequence, the reactor must plan the responses to the actor's arguments before the actor ends her communication shift. As Levinson claims, "the implication of the slow production system is that, in interactive language use, comprehension and production overlap-one must plan while still listening and predicting what the rest of the incoming turn will contain" (Levinson, 2016, p. 7). If the reactor is already planning how to reply while the actor is still talking, this means that the reactor understands via inferencing a great deal of what the actor intends to say before she has finished her communication shift. Putting it differently, some aspects of language processing are largely independent of what the speaker actually says.

This is the ultimate foundation of the hypothesis claiming that human communication is based on the speaker's intentions as originally proposed by Grice (1957) and later found in Sperber and Wilson's relevance theory $(1986,2002)$ and subsequent work by Scott-Phillips $(2015,2017)$ and many others. In the absence of a structured expressive code (i.e., grammar), as hypothesized by many for the initial stages in the evolution of human language, characterized by single-word utterances, the burden of communicative exchanges, and particularly the interpretation of the evidence of what the speaker intends to communicate, would have relied on our pre-grammatical cognitive abilities and devices. Among the cognitive devices sketched above (Section 5), we wish to highlight two that are especially relevant in this respect: ToM and MTT. Our ToM is the major component of our social intelligence, namely, the metarepresentational system that enables us to attribute mental states to others (Sperber, 2000; Sperber \& Wilson, 2002). Several scholars have suggested that such a device is a cognitive precursor of language (e.g., Corballis, 2017; Origgi \& Sperber; 2000; Scott-Phillips, 2015, 2017). Investigations that showed that forms of mindreading are also present in non-human primates 
(e.g., Buttelmann, Buttelmann, Carpenter, Call, \& Tomasello, 2017; Krupenye, Kano, Hirata, Call, \& Tomasello, 2016; Kano et al. 2019), even if in form simpler than ToM (such as vicarious representations, Nanay, 2020), contribute to corroborate this view. Of great importance for our intents are the studies attesting the role of ToM in children's development of persuasive strategies (Bartsch \& London, 2000; Slaughter, Peterson, \& Moore, 2013; Stato and Wakebe, 2012; To, Yim, Lam, \& Iao, 2016).

Nonetheless, as reasoned by Ferretti (2016), a ToM system is not sufficient to guarantee human communication, as mutual persuasion also requires a projection device into the future (to anticipate what the interlocutor is about to say) and into the past (to constantly monitor if what she is saying is in line with what she has already said). The MTT system is the cognitive device that allows us to project backward and forward in time (Michaelian, 2016; Suddendorf \& Corballis, 1997; Tulving, 1985, 2007). It is composed of two abilities that are strongly interrelated: the EM, responsible for reliving past events (Tulving, 1985), and the episodic future thinking (Atance \& O'Neill, 2001), which allows simulation of possible future scenarios. Comparative studies have revealed that non-human primates can (to a greater or lesser extent) project themselves backward and forward in time (e.g., Kano \& Hirata, 2015; Mulcahy \& Call, 2006). As in the case of the ToM system, these studies suggest that the MTT system is also partly independent from language and that it can be considered as another of its cognitive precursors (Corballis, 2020; Ferretti et al., 2017). From these considerations, it transpires that the ToM and the MTT systems do not only support the proper functioning of language but, most likely, are part of the cognitive equipment that guided the early forms of typically human communication. In turn, consistent with the postulated feedback loop, we expect that the emergence of early forms of language/grammar contributed to further honing and sophistication of these cognitive devices. Consistent with this perspective are studies on the relationship between language and ToM (Heyes \& Frith, 2014; Moore, 2017; Woensdregt et al., 2020) as well as studies considering how the emergence of elaborated ways of expressing time through grammatical devices (e.g., verbal tenses) contributed to augment our mental travel abilities. Even if our hypothesis is that MTT is a structural precondition of language (Ferretti, 2016; Ferretti \& Adornetti, 2020), we argue that the origin of language activated a coevolutive process with effects on MTT structure and functioning. Following Suddendorf et al. (2009), we suspect that: "Language (...) coevolved with mental time travel to allow the sharing of episodic information, sometimes to the point that we confuse events that have actually happened in our lives with those told to us by others, or even with those gleaned from fictional accounts" (p. 1321). Under this view, the first (proto-conversational) forms of human communication, at the beginning without syntax and later relying on simple, two-slot grammars (see e.g., Progovac \& Benítez-Burraco, 2019, and references there), would have been heavily reliant on the functioning of a variety of cognitive devices, the precursors of which would have been pre-grammatical in nature, with parallels in other species.

\subsection{The need for a complex grammar}

As discussed above, these cognitive systems on their own cannot fully account for the character of persuasive reciprocity typically found in human conversations. Persuasive 
reciprocity arguably became optimized when the medium of expression, that is, the communicative code became increasingly complex. Specifically, we contend that defending one's beliefs from the beliefs of others is achieved more efficiently when one can articulate and express one's thoughts in a more precise and sophisticated way. To understand how it is possible to improve persuasive ability, we must return to the idea that the persuasive power of communication is largely linked to the argumentative structure of conversation. Since argumentation is the product of reasoning and since reasoning is a form of inference, what follows is that a way to enhance argumentative skills is to enhance inferential skills. An empowerment of this type involves the representational structures involved in inferential processes. Inferences, in fact, are the kind of mental operations that apply at best to specific representational structures, the propositional ones. Indeed, as Sperber and Wilson (1986) stated:

"There is a very good reason for anyone concerned with the role of inference in communication to assume that what is communicated is propositional: it is relatively easy to say what propositions are, and how inference might operate over propositions. No one has any clear idea how inference might operate over non-propositional objects: say, over images, impressions or emotions. Propositional contents and attitudes thus seem to provide the only relatively solid ground on which to base a partly or wholly inferential approach to communication" (Sperber \& Wilson, 1986, p. 57).

To this end, the combinatory power of grammar is especially useful. The origin of syntactically complex expressive structures is what allows us to enhance argumentative skills through the enhancement of inferential skills. In this perspective, the origin of pragmatics (the use of language in conversational contexts) is closely connected to the origin of syntax. Accordingly, in our proposal: (a) initially, there is no grammar, but still some pragmatic persuasion is possible via pre-linguistic cognitive devices; (b) then there emerge simple grammars, correlated with better pragmatic possibilities, including rudimentary, primitive verbal exchanges; and (c) the pressure for better persuasion gives incentive to the emergence of more complex grammars (as well as vice versa: More elaborate grammars provide better tools for persuasion). With the advent of such highly structured expressive system (c), humans gained their best control of reactive aggression and ultimately the conflict avoidance strategies, which were only roughly achieved by the proto-conversational forms of communication. This is why we have postulated this additional step (c) in the evolution of human conversational abilities and ultimately of the modern use of language: the transition to conversational forms characterized by persuasive reciprocity relying on enhanced grammatical structures.

The final part of this section addresses the problem of how and why grammar became more sophisticated, ultimately enabling modern-like conversational interactions, under the specific effects of self-domestication. In brief, according to Benítez-Burraco and Progovac (2021), as self-domestication worked toward decreasing reactive aggression, it gradually enhanced longrange connectivity of our brain networks, and particularly reinforced the control of cortical structures over subcortical structures, which is needed for suppression of aggressive impulses. This evolutionary development, in turn, stimulated cross-modality, considering that reactive aggression and cross-modality rely on similar, overlapping brain networks. The selective advantage of the earliest, simplest forms of grammar (with their high emotional load and raw metaphoricity) would have reinforced this path toward enhanced cross-modality even further, 
contributing to increased grammar complexity, as well as to a gradual reduction in physical aggression, now being replaced by verbal aggression. As noted in Section 4 above, a second but related source of grammar complexity comes from the increased grammaticalization processes, which also rely on metaphorical extension, and thus on enhanced cross-modality, as well as on our increasingly sophisticated inferential abilities.

Such a view is consistent with the idea of "syntax in conversation" carried out by interactional linguistics (Thompson, Fox, \& Couper-Kuhlen, 2015), a perspective according to which "syntax cannot be fully understood without an account of its interactional [environment] in a turn" (Lindström, 2009, p. 99). Following Thompson and Couper-Kuhlen (2005), the interactional nature of this "grammar at work" can be analyzed from different perspectives. Of great importance is the construction of clauses since "the clause is (...) the locus of interaction in everyday conversation" (Thompson \& Couper-Kuhlen, 2005, p. 484). In their view, "the clause can be thought of as a crystallization of solutions to the interactional problem of signaling and recognizing social actions" (Thompson and Couper-Kuhlen, 2005, p. 484). In such a perspective, the conversational context is the evolutionary trigger of grammar sophistication, but as noted, this context would have become enriched by our self-domestication. This is a process in constant development: "since clauses are shaped in contingent situations of interaction, grammar is constantly being shaped and re-shaped, constantly undergoing revision and redesign as it is deployed in everyday talk" (Thompson \& Couper-Kuhlen, 2005, p. 482).

In summary, our proposal is that grammar and pragmatics co-exist in a relation of mutual evolution, with self-domestication favoring this co-evolutionary process. On the one hand, the reduction in (reactive) aggression linked to our enhanced self-domestication favored the creation of the conversational context that enables mutual persuasion via a sophisticated system of expression, that is, grammar. On the other hand, a sophisticated grammar emerges as a tool for strengthening conversation and, through exchanges of mutual persuasion, for reducing aggression. Under this view, self-domestication stimulates the co-evolution of pragmatics and grammar via its impact on the conversation.

\section{Corroborating evidence for the model: Cognitive disorders}

Proposals regarding language evolution are notoriously difficult to test, although some indirect evidence (and some potential testing grounds) can (and should) be provided. Certain aspects of cognitive/language disorders have been regularly regarded as confident proxies of (specific stages of) modern cognition/language evolution. The reason is the robust link that exists between evolution and abnormal development, with recently evolved aspects of the human phenotype being more susceptible to developmental damage because of their reduced resilience (see Toro et al., 2010, for discussion regarding autism; see Benítez-Burraco \& Boeckx, 2014, for further arguments for using disorders as proxies). In fact, most, if not all, cognitive disorders entailing abnormal patterns of brain development and organization, as well as abnormal patterns of social functions, also exhibit problems with figurative language and language use in general (see Benítez-Burraco, 2017b, for discussion). Importantly for our view here, they also tend to show abnormal management of aggression and, more 
generally, altered features of self-domestication (e.g., Benítez-Burraco, Lattanzi, \& Murphy, 2016, 2017). This is why we wish to consider these disorders as useful proxies of (specific stages of) modern pragmatics evolution under the effects of human self-domestication.

Autism spectrum disorder (ASD) is an illustrative example. Individuals with ASD have difficulties with structural aspects of language (Bourguignon, Nadig, \& Valois, 2012; Eigsti et al., 2007; Tager-Flusberg, 2006; Tager-Flusberg, Paul, \& Lord, 2005), which have been related to oromotor deficits (Belmonte et al., 2013), reduced semantic priming (Preissler, 2008), issues with phonological processing (Lindgren, Folstein, Tomblin, \& Tager-Flusberg, 2009), and/or impairment of procedural memory (Walenski, Tager-Flusberg, \& Ullman, 2006). At the same time, they also exhibit difficulties with understanding abstract concepts and metaphors (Dodd, 2005, p. 47; Jordan, 2010), which have been hypothesized to result from a deficit in the ToM system (Happé, 1995), and/or a reduced semantic competence (Norbury, 2004). Importantly for our concerns here, as highlighted by Volden (2017), people on the autism spectrum do not exhibit a unique underlying pragmatic deficit; rather, they show a series of communicative difficulties, including atypical conversational exchanges, which, taken together, are suggestive of diverse underlying deficits in the use of language. Accordingly, in ASD we have the opportunity to focus on specific pragmatic disabilities (e.g., difficulties with figurative language, turn-taking, repair strategies, topic preservation, topic shift, narrative coherence, etc.) with the aim of evaluating, on a case-by-case basis, how they impact upon the use of language and how they relate to specific cognitive systems. For example, Ferretti et al. (2018) and Marini et al. (2019) have highlighted a correlation in children on the autism spectrum between deficits in narrative coherence and the impairment of the MTT system. Overall, these circumstances make this clinical population a potential testing ground for the analysis of the evolution of the pragmatic aspects of language under the effects of self-domestication as we have outlined in the previous section.

Here, we will focus again on the persuasive reciprocity characterizing human conversational exchanges. Studies on the conversational difficulties experienced by people on the autism spectrum (e.g., Sng et al., 2018) have highlighted several anomalies of interest, including the atypical conversational repair strategies (Volden, 2004), as well as difficulties with initiating and sustaining conversation (Jones \& Schwartz, 2009). Likewise, there are also difficulties with topic preservation/shift and turn-taking. According to Sng et al. (2018), people on the autism spectrum "tended to have difficulties preserving a conversation by extending a topic or offering novel information and were more likely to resist topic shifts by persevering and making bizarre comments" (p. 20). More generally, their communication frequently appears to reach an impasse, with no possibility of progressing forward. As a consequence, even people with high-functioning ASD often incur longer turn-taking gaps and pauses and reduced synchrony with the interlocutor when talking, with these atypical features positively correlating with ASD symptoms (Ochi et al., 2019). Turn-taking impairments correlate with difficulties to take and defend one's point of view in conversation: Such a difficulty is expected to undermine the exchange of roles between actor and reactor that we have considered to be the main feature of mutual persuasion in conversation. Likewise, people on the autism spectrum experience difficulties in reading the speaker's intention, which, as we have seen, is the basic tenet of relevance theory (Happé, 1993, 1994, 1995). 
With that in mind, given the role we ascribe to ToM and MTT in persuasive conversation (see the previous section), a litmus test of our hypothesis concerns the possibility that these cognitive systems are impaired in individuals with ASD. As for ToM, neuroscientific research unveiled that the neural regions that underlie the ability to mentalize, which include the bilateral temporal-parietal junction, the posterior superior temporal sulcus, and the medial prefrontal cortex, are characterized by atypical activation in individuals with ASD (e.g., Castelli, Frith, Happé, \& Frith, 2002; Schultz et al., 2003). Notably, it has been revealed that these brain regions show atypical activation also when people on the autism spectrum are faced with interpreting the communicative intentions of others, as in the case of irony (e.g., Colich et al., 2012; Wang, Lee, Sigman, \& Dapretto, 2006, 2007), as well as during the reading of narrative passages requiring inferences based on the characters' intentions (Mason et al., 2008). Studies on the key role of ToM to explain the deficit of persuasion skills of people on the autism spectrum are of great interest to our purposes (To et al., 2016). Although to a lesser extent than the studies involving ToM, the difficulty of projection in time experienced by people with ASD has also been highlighted in various investigations (Crane \& Goddard, 2008; Ferretti et al., 2018; Lind \& Bowler, 2010; Marini et al., 2016, 2019). Accordingly, people on the autism spectrum show difficulties with re-experiencing past events, implicating EM (Cooper \& Simons, 2019) as well as a deficit in anticipating personal future scenarios, implicating episodic foresight (Sheppard, Bruineberg, Kretschmer-Trendowicz, \& Altgassen, 2018; Terrett et al., 2013). As we noted in Section 5, the hippocampus is the main neural substrate of our ability to project backward and forward in time. From this consideration, it seems reasonable to hypothesize that difficulties involving MTT affecting people on the autism spectrum are linked to hippocampal abnormalities. Investigations finding reduced hippocampal functional connectivity in this clinical population seem to corroborate this view (e.g., Cooper et al., 2017).

To the best of our knowledge, the potential links between ToM, MTT, and conversational (dis)abilities in ASD have not been explored in any detail. However, in the light of the considerations made so far, there are good reasons to hypothesize that such a link could exist and that studying it should result in a better understanding of the conversational difficulties experienced by people on the autism spectrum. Importantly, as we have also discussed, the acquisition of pragmatic abilities does not only depend on specific cognitive abilities (mostly, the capacity for cross-modal thinking as well as the capacity to understand others' intentions): It also demands a rich social environment and appropriate socialization abilities, for example, sensitivity to social relations and social cues (Burnside, Wright, \& Poulin-Dubois, 2017; Syal \& Finlay, 2011; Zufferey, 2015, and references therein). Socialization patterns are typically deficient in people on the autism spectrum (Bailey, Phillips, \& Rutter, 1996). This is expected to be a second crucial source of the conversational issues (and more generally, the pragmatic deficits) exhibited by people with ASD.

Importantly for our hypothesis, ASD can be seen as a disorder implicating atypical features of self-domestication, more precisely attenuated features. Accordingly, people on the autism spectrum may show atypical face features that correlate with cognitive impairment and language regression (Obafemi-Ajayi et al., 2015); higher brain volumes correlating with lower functioning abilities (Lewis et al., 2013; Nordahl et al., 2011; Sacco et al., 2015); increased 
reactive aggression correlating with lower cognitive outcomes (Farmer et al., 2015; Hill et al., 2014); atypical response to the social environment, including an atypical response of the hypothalamic-pituitary-adrenal axis (Spratt et al., 2012; Taylor \& Corbett, 2014); and/or early overgrowth, contrasting with the neotenic features brought about by self-domestication (Chawarska et al., 2011; Van Daalen et al., 2007). Moreover, many candidate genes for ASD show signals of positive selection in domesticated animals, while many candidates for animal domestication exhibit altered expression profiles in the brains of people on the autism spectrum (see Benítez-Burraco et al., 2016, for details). These circumstances offer a promising window into the ultimate causes of the pragmatic deficits found in ASD.

Our proposal is that the pragmatic deficits typically observed in people on the autism spectrum (as well as the other disparate characteristics also found in ASD as mentioned above) result, at least in part, from the impairment of the common underlying biological mechanism that was remodeled during our recent evolutionary history, namely, human self-domestication. As with the other predictions that follow from our proposal, this possibility needs to be tested too. Accordingly, common candidates for ASD and self-domestication could be studied in vitro and in vivo to see whether they exhibit ASD-specific mutations or abnormal expression patterns. Likewise, it is of interest to investigate further the physiological mechanisms involved in stress response in people on the autism spectrum and its effects on behavior and cognition. A further empirical study that might corroborate our hypothesis could evaluate the correlation between aggression and conversation. As the main trait of self-domestication is the reduction of aggression, and since we claimed that the use of language in a conversational context is an effective way to reduce aggression, ASD could be an interesting case study. As mentioned above, independent investigations attested that ASD presents traits of reactive aggression (Fitzpatrick, Srivorakiat, Wink, Pedapati, \& Erickson, 2016; Hirota, Deserno, \& McElroy, 2020) as well as conversational deficits (Sng et al., 2018). In the light of these findings, it is possible to hypothesize that at least some aspects of reactive aggression in people on the autism spectrum might be linked to their difficulties in assuming and defending their own point of view in conversation. At the same time, under this view, pragmatic (as well as social) difficulties in ASD can illuminate certain specific aspects of the evolution of human pragmatics, arguably under the effects of self-domestication. For instance, we can hypothesize that during the initial stages of language evolution, when reactive aggression was still high, figurative uses of language were scarce and the conversational exchanges were much less fluid, as actually seen in people on the autism spectrum.

\section{Concluding remarks}

In parallel to our proposal regarding the emergence of modern grammars (Benítez-Burraco \& Progovac, 2020; Progovac \& Benítez-Burraco, 2019), here, we propose that modern uses of language (pragmatics) also evolved gradually in our species under the effects of human self-domestication, where changes in: (a) aggression types and levels; (b) grammar structure; and (c) language use were intertwined in a complex feedback loop, and where changes in conversational exchanges played an active role in this process. Hence, the reduction in reactive 
aggression, which is a key player in self-domestication processes, also seems to be an essential factor not only in evolving sophisticated grammars but also in evolving sophisticated turntaking and complex inferential abilities, all of which demand a fine-tuned coordination, which is favored by longer and more frequent contacts enabled by enhanced self-domestication.

In this paper, we also stress the return effect of conversation, and language more generally, on self-domestication, in particular, the role of conversational strategies in reducing physical aggression. Specifically, we conclude that, in communicative exchanges governed by persuasive reciprocity, the reduction of reactive aggression is closely linked to the replacement of physical aggression with (proactive forms of) verbal argumentation. In this sense, our approach is a multi-prong approach to the evolution of language, which assigns an active role to each factor, as well as their mutual interactions. As such, our proposal adheres to gene-culture co-evolution models and is also compatible with the cultural niche proposals.

So far, we have identified two potential sources of corroborating evidence and testing grounds for this proposal: (a) extant languages spoken by isolated human groups, showing a greater reliance on implicit meanings and seemingly demanding more involvement of inferential capabilities; and (b) relevant cognitive disorders, which present atypical features of self-domestication, as well as atypical pragmatics, and social functioning. In our view, both domains, when studied with these specific hypotheses in mind, are expected to shed new light on several aspects of the evolution of human pragmatics under the effects of selfdomestication.

\section{Conflict of interest}

The authors declare no conflict of interest. Author Contributions

Antonio Benítez-Burraco, Francesco Ferretti, and Ljiljana Progovac: Conceptualization, methodology, investigation, and writing.

\section{Data Availability Statement}

The data and material used in the analyses are presented as a list of bibliographical references.

\section{Notes}

1. The social behavior of extant primates can be subject to direct inquiry. Most comparative studies concern bonobos versus chimps, which are the closest living species to us. Compared to chimps, bonobos exhibit reduced reactive aggression, i.e., an aggressive impulse to react in the moment out of fear or anger (Hare, Wobber, \& Wrangham, 2012). Also, they show a minimal level of proactive (i.e., premeditated) aggression, which is common among chimps (Wilson et al., 2014). As we discuss, this stands in contrast with humans, particularly during the Holocene, as humans frequently participate in planned conflicts involving high rates of violence. As noted by Wrangham (2018), humans share 
a higher propensity for proactive aggression with chimps but a lower propensity for severe reactive aggression with bonobos. As we also argue in Section 3, the evolutionary trajectories and interplays of these two distinct types of aggression in the descent of humans (in the context of the self-domestication hypothesis) are important for accounting for the emergence of modern languages and uses of language. With regards to extinct hominins, (pro)social behavior needs to be inferred from indirect evidence, mostly signs of aggression, such as evidence of injuries or violent death, and from the nature of social networks. As expected, most available data concerns Neanderthals, the closest extinct species to us. There is some evidence of violent deaths among older species, as attested example with one of the individuals from the Sima de los Huesos, belonging to the Neanderthal clade (Salas et al., 2015), but this evidence is very limited. As discussed by Eastabrook and Frayer (2014), the amount of trauma among Neanderthals fits within the range of modern hunter-gatherer populations. There is some evidence that a subset of these traumatic injuries was due to interpersonal violence (see Trinkaus, 2012, for review). Regarding socialization patterns that could be inferred from physical features, such as brain morphology suggestive of a social brain, the evidence is ambivalent and indirect. Most researchers would agree that Neanderthal networks were less extended than human networks, being seemingly restricted to very local groups (e.g., Gamble, 1999, 1999), although archaeological remains from late periods suggest that the social organization of the last Neanderthals might not have been so simple (see Wragg Sykes, 2012, for discussion).

2. It is true that in present times, when most of us are not overly aggressive, verbal aggression can in fact precipitate physical aggression. However, first, we believe that at the point when language just started emerging, and the derogatory forms of language were creative and novel, arguably also humorous, their primary effect was to reduce tensions and to avoid physical aggression. Second, even in present times, it has been argued that (ritual) insult in public in fact very rarely (statistically speaking) leads to physical altercations and that it often constitutes a genre of fighting/challenging in itself, mostly involving various types of ritualized posturing (e.g., Locke, 2008; Marsh, 1978).

3. As noted by cognitive linguists, conceptual associations like metaphors and metonyms also underlie many structural aspects of modern languages (Croft \& Cruse, 2004; Lakoff \& Johnson, 1980). Some authors have specifically claimed that our enhanced ability for merging concepts and creating new concepts can be linked to the core computational operation of natural languages (e.g., Boeckx \& Benítez-Burraco, 2014).

4. To give just one example, we recall the evidence of positive selection in genes belonging to pathways related to long-term potentiation (implicated in memory and learning abilities) in European samples during the last 6,000 years (Chekalin et al., 2019), which have been hypothesized to be linked in part to the spread of Indo-European languages, associated with exoteric end of the esoteric-exoteric language scale. As also noted, signals of positive selection in candidates for domestication have also been found for this period and this region (Benítez-Burraco et al. in press).

5. As pointed out by Dor (2017), both cooperation and competition (e.g., lying) are relevant for the evolution of language/cognition, as without both forces acting upon us, humans 
would have evolved into much simpler, more unidimensional beings in this respect. As mentioned in Wacewicz et al. (2017), display and courtship are also directly relevant for the evolution of language (Dessalles, 2007), and these typically involve competition. So does verbal aggression, as discussed in the context of the evolution of early grammars, and in the context of sexual selection, by, e.g. Progovac and Locke (2009), Progovac (2016), and Progovac and Benítez-Burraco (2019). Much more on the role of cooperation versus competition is found in Section 8.

6. Rakhlin and Progovac (2020) explore the possibility that many of human cognitive functions, including the consideration of MTT and the ToM, have basic foundational precursors in non-linguistic mechanisms but that various milestones in the acquisition of syntax (by children) hone these basic cognitive strategies into much more precise, richer devices. This is consistent with the view that language not only relies on those core cognitive precursors but also that it acts as the augmenter of such non-verbal cognition, the hypothesis consistent with the core knowledge theory of cognitive development (e.g., Spelke, 2003; Spelke \& Kinzler, 2007). This view is furthermore consistent with the main idea of a feedback loop as explored in this paper. Moreover, with respect to neuroanatomy, much of the hippocampus, essential for declarative memory formation, is formed prior to birth. However, its different regions exhibit uneven postnatal development, with some demonstrating prolonged maturation. In this respect, EM is conditional upon the maturation of the entire hippocampal system during early childhood (Lavenex \& Banta Lavenex, 2013). This is also consistent with the finding of precursors of both ToM and MTT in animals (e.g., Corballis 2013, 2018, 2019a, 2019b on MTT).

7. In this article, we argue that the mutually persuasive character of conversation is largely governed by the ability of interlocuters to argue and counterargue in their communicative exchanges. That said, argumentation is neither the only tool for persuasion, nor is it the oldest tool used by humans to promote their specific way of communication. Elsewhere (Ferretti \& Adornetti, 2021; Ferretti et al., submitted), we have argued that ancient humans used narrative forms of persuasion and began to tell stories in the form of pantomime before the advent of verbal language and, therefore, before possessing the adequate structural resources to communicate through argumentative forms of persuasion. While it can be a powerful tool for persuasion, storytelling, however, is not nearly as efficient a tool for persuasive reciprocity as is conversation. Similarly, the hypothesized early uses of crude two-slot grammars for verbal aggression, even though very useful in replacing physical aggression with verbal aggression at this early stage, would only have had a limited usefulness for persuasion, as their reciprocity would have been rather limited. In fact, just as these grammars were somewhere midway between no grammar at all, and sophisticated hierarchical grammars, so can their turn-taking/persuasive capacity be seen as somewhere midway between unidirectional proto-conversation (characterizing other species), and fully reciprocal conversation. In this respect, the invention of a new expressive system (verbal language with more systematically structured grammars) proved immensely useful for the argumentative form of persuasion. 
8. Because the topic of this paper is not language structure per se, but language use, here we provide only a brief summary of our model, which can be found explicated in Progovac and Benítez-Burraco, 2019; Benítez-Burraco \& Progovac, 2020, 2021.

\section{References}

Adornetti, I. (2015). The phylogenetic foundations of discourse coherence: A pragmatic account of the evolution of language. Biosemiotics, 8(3), 421-441.

Amici, F., Sánchez-Amaro, A., Sebastián-Enesco, C., Cacchione, T., Allritz, M., Salazar-Bonet, J., \& Rossano, F. (2019). The word order of languages predicts native speakers' working memory. Scientific Reports, 9(1), 1124. https://doi.org/10.1038/s41598-018-37654-9

Andelman, F., Hoofien, D., Goldberg, I., Aizenstein, O., \& Neufeld, M. Y. (2010). Bilateral hippocampal lesion and a selective impairment of the ability for mental time travel. Neurocase, 16(5), 426-435.

Asher, N., \& Lascarides, A. (2013). Strategic conversation. Semantics and Pragmatics, 6, 2-1.

Atance, C. M., \& O'Neill, D. K. (2001). Episodic future thinking. Trends in Cognitive Sciences, 5(12), 533-539.

Atkinson, J. M., Heritage, J. (Eds.) (1984). Structures of social action. Cambridge: Cambridge University Press.

Atzil, S., Gao, W., Fradkin, I., \& Barrett, L. F. (2018). Growing a social brain. Nature Human Behaviour, 2(9), 624-636. https://doi.org/10.1038/s41562-018-0384-6

Bailey, A., Phillips, W., \& Rutter, M. (1996). Autism: Towards an integration of clinical, genetic, neuropsychological, and neurobiological perspectives. Journal of Child Psychology and Psychiatry and Allied Disciplines, 37(1), 89-126.

Bartsch, K., \& London, K. (2000). Children's use of mental state information in selecting persuasive arguments. Developmental Psychology, 36(3), 352.

Bednarik, R. G. (2014). Doing with less: Hominin brain atrophy. Homo, 65, 433-449. https://doi.org/10.1016/j. jchb.2014.06.001

Beecher, M. D. (2021). Why are no animal communication systems simple languages? Frontiers in Psychology, 12, 602635. 10.3389/fpsyg.2021.602635

Belmonte, M. K., Saxena-Chandhok, T., Cherian, R., Muneer, R., George, L., \& Karanth, P. (2013). Oral motor deficits in speech-impaired children with autism. Frontiers in Integrative Neuroscience, 7, 47.

Benítez-Burraco, A. (2017a). Grammaticalization and language evolution: Focusing the debate. Language Sciences, 63, 60-68.

Benítez-Burraco, A. (2017b). Figurative language, language disorders, and language(s) evolution. Frontiers in Psychology, 8, 1713.

Benítez-Burraco, A. (2021). Mental time travel, language evolution, and human self-domestication. Cognitive Process. https://doi.org/10.1007/s10339-020-01005-2

Benítez-Burraco, A., \& Boeckx, C. (2014). Language disorders and language evolution: Constraints on hypotheses. Biological Theory, 9, 269-274. https://doi.org/10.1007/s13752-013-0148-5

Benítez-Burraco, A., Chekalin, E., Bruskin, S., Tatarinova, T., \& Morozova, I. (in press) Recent selection of candidate genes for mammal domestication in Europeans and language change in Europe: A hypothesis. Annals of Human Biology.

Benítez-Burraco, A., \& Kempe, V. (2018). The emergence of modern languages: Has human self-domestication optimized language transmission? Frontiers in Psychology, 17(9), 551. https://doi.org/10.3389/fpsyg.2018. 00551

Benítez-Burraco, A., \& Progovac, L. (2020). A four-stage model for language evolution under the effects of human self-domestication. Language \& Communication, 73, 1-17. https://doi.org/10.1016/j.langcom.2020.03.002

Benítez-Burraco, A., \& Progovac, L. (2021). Language evolution: Examining the link between crossmodality and aggression through the lens of disorders. Philosophical Transactions of the Royal Society B, 376, 20200188. https://doi.org/10.1098/rstb.2020.0188 
Benítez-Burraco, A., Di Pietro, L., Barba, M., \& Lattanzi, W. (2017). Schizophrenia and human selfdomestication: An evolutionary linguistics approach. Brain Behavior and Evolution, 89(3), 162-184

Benítez-Burraco, A., Lattanzi, W., \& Murphy, E. (2016). Language impairments in ASD resulting from a failed domestication of the human brain. Frontiers in Neuroscience, 10, 373. https://doi.org/10.3389/fnins.2016. 00373

Boeckx, C., \& Benítez-Burraco, A. (2014). The shape of the human language-ready brain. Frontiers in Psychology, 5, 282.

Boeckx, C. (2011). The emergence of the language faculty, from a biolinguistic point of view. In M. Tallerman \& K. Gibson (Eds.), Oxford handbook of language evolution (pp. 492-501). Oxford: Oxford University Press.

Bouckaert, R., Lemey, P., Dunn, M., Greenhill, S. J., Alekseyenko, A. V., Drummond, A. J., ... Atkinson, Q. D. (2012). Mapping the origins and expansion of the Indo-European language family. Science, 337(6097), 957-960. https://doi.org/10.1126/science.1219669

Bourguignon, N., Nadig, A., \& Valois, D. (2012). The biolinguistics of autism: Emergent perspectives. Biolinguistics, 6, 124-165.

Bradbury, J. W., \& Vehrencamp, S. L. (1998). Principles of animal communication. Sunderland, MA: Sinauer.

Burge, T. (1993). Content preservation. Philosophical Review, 101, 457-488

Burnside, K., Wright, K., \& Poulin-Dubois, D. (2017). Social motivation and implicit theory of mind in children with autism spectrum disorder. Autism Research, 10, 1834-1844. https://doi.org/10.1002/aur.1836

Buttelmann, D., Buttelmann, F., Carpenter, M., Call, J., \& Tomasello, M. (2017). Great apes distinguish true from false beliefs in an interactive helping task. Plos One, 12(4), e0173793. https://doi.org/10.1371/journal.pone. 0173793

Campbell, L., \& Janda, R. (2001). Introduction: Conceptions of grammaticalization and their problems. Language Sciences, 23, 93-112

Corballis, M. C. (2013). Mental time travel: a case for evolutionary continuity. Trends in Cognitive Sciences, 17(1), 5-6. https://doi.org/10.1016/j.tics.2012.10.009

Corballis, M. C. (2018). Space, time, and language. Cogn Process, 19(Suppl 1), 89-92. https://doi.org/10.1007/ s10339-018-0878-1

Corballis, M. C. (2019a). Mental time travel, language, and evolution. Neuropsychologia, 134, 107202. https: //doi.org/10.1016/j.neuropsychologia.2019.107202

Corballis, M. C. (2019b). Language, memory, and mental time travel: an evolutionary perspective. Frontiers in Human Neuroscience, 13, 217. https://doi.org/10.3389/fnhum.2019.00217

Carruthers, P. (2006). The architecture of mind. Oxford: Oxford University Press.

Castelli, F., Frith, C., Happé, F., \& Frith, U. (2002). Autism, Asperger syndrome and brain mechanisms for the attribution of mental states to animated shapes. Brain, 125(8), 1839-1849.

Chawarska, K., Campbell, D., Chen, L., Shic, F., Klin, A., \& Chang, J. (2011). Early generalized overgrowth in boys with autism. Archives of General Psychiatry, 68, 1021-1031.

Chekalin, E., Rubanovich, A., Tatarinova, T. V., Kasianov, A., Bender, N., Chekalina, M., ... Morozova, I. (2019). Changes in biological pathways during 6,000 years of civilization in Europe. Molecular Biology and Evolution, 36(1), 127-140. https://doi.org/10.1093/molbev/msy201

Choi, J. -K., \& Bowles, S. (2007). The coevolution of parochial altruism and war. Science, 318, 636-640

Cieri, R. L., Churchill, S. E., Franciscus, R. G., Tan, J., \& Hare, B. (2014). Craniofacial feminization, social tolerance, and the origins of behavioral modernity. Current Anthropology, 55, 419-443.

Clarke, E., \& Heyes, C. (2017). The swashbuckling anthropologist: Henrich on the secret of our success. Biology \& Philosophy, 32, 289-305. https://doi.org/10.1007/s10539-016-9554-y

Colich, N. L., Wang, A. T., Rudie, J. D., Hernandez, L. M., Bookheimer, S. Y., \& Dapretto, M. (2012). Atypical neural processing of ironic and sincere remarks in children and adolescents with autism spectrum disorders. Metaphor and Symbol, 27(1), 70-92.

Cooper, R. A., \& Simons, J. S. (2019). Exploring the neurocognitive basis of episodic recollection in autism. Psychonomic Bulletin \& Review, 26(1), 163-181. https://doi.org/10.3758/s13423-018-1504-z 
Cooper, R. A., Richter, F. R., Bays, P. M., Plaisted-Grant, K. C., Baron-Cohen, S., \& Simons, J. S. (2017). Reduced hippocampal functional connectivity during episodic memory retrieval in autism. Cerebral Cortex, 27(2), 888902. https://doi.org/10.1093/cercor/bhw417

Corballis, M. C. (2017). The truth about language. Chicago: University of Chicago Press.

Corballis, M. C. (2020). Mental time travel as a precursor to language. Paradigmi, 38(2), 237-249.

Crane, L., \& Goddard, L. (2008). Episodic and semantic autobiographical memory in adults with autism spectrum disorders. Journal of Autism and Developmental Disorders, 38(3), 498-506.

Croft, W., \& Cruse, D. A. (2004). Cognitive linguistics. Cambridge: Cambridge University Press.

Davidson, D. (1984). Radical interpretation. In Inquiries into truth and interpretation (pp. 125-140). Oxford: Oxford University Press.

Dawkins, R., \& Krebs, J. R. (1978). Animal signals: Information or manipulation. Behavioural Ecology: An Evolutionary Approach, 2, 282-309.

de Barros Damgaard, P., Martiniano, R., Kamm, J., Moreno-Mayar, J. V., Kroonen, G., Peyrot, M., ... Willerslev, E. (2018). The first horse herders and the impact of early Bronze Age steppe expansions into Asia. Science, 360(6396), eaar7711. https://doi.org/10.1126/science.aar7711

De Villiers, J. G. (2005). Can language acquisition give children a point of view? In J. W. Astington \& J. A. Baird (Eds.), Why language matters for theory of mind (pp. 186-219). Oxford: Oxford University Press.

Dessalles, J. -L. (2007). Why We Talk-the Evolutionary Origins of Language (English edition of 'Aux origines du langage'). Oxford: Oxford University Press.

Dodd, E. (2005). Understanding Autism. Sydney: Elsevier Australia.

Dor, D. (2017). The role of the lie in the evolution of human language. Language Sciences, 63, 44-59.

Dressler, W. W. (2020). The construction of the cultural niche: A biocultural model. American Journal of Human Biology, 32(4), e23311. https://doi.org/10.1002/ajhb.23311

Dunbar, R. I. (2009). The social brain hypothesis and its implications for social evolution. Annals of Human Biology, 36(5), 562-572. https://doi.org/10.1080/03014460902960289

Eigsti, I. M., Bennetto, L., \& Dadlani, M. B. (2007). Beyond pragmatics: morphosyntactic development in autism. Journal of Autism and Developmental Disorders, 37(6), 1007-1023. https://doi.org/10.1007/s10803-006-02392

Estabrook, V. H., \& Frayer, D. W. (2014). Trauma in the Krapina Neandertals: Violence in the middle Paleolithic? In C. Knüsel \& M. Smith (Eds.), The Routledge handbook of the bioarchaeology of human conflict (pp. 67-89). Abingdon: Routledge.

Farmer, C., Butter, E., Mazurek, M. O., Cowan, C., Lainhart, J., Cook, E. H., DeWitt, M. B., \& Aman, M. (2015). Aggression in children with autism spectrum disorders and a clinic-referred comparison group. Autism, 19, 281-291.

Falk, E. B., \& Bassett, D. S. (2017). Brain and social networks: Fundamental building blocks of human experience. Trends in Cognitive Sciences, 21(9), 674-690. https://doi.org/10.1016/j.tics.2017.06.009

Ferretti, F. (2016). The social brain is not enough: On the importance of the ecological brain for the origin of language. Frontiers in Psychology, 7, 1138.

Ferretti, F., Adornetti, I., Chiera, A., Nicchiarelli, S., Magni, R., Valeri, G., \& Marini, A. (2017). Mental Time Travel and language evolution: A narrative account of the origins of human communication. Language Sciences, 63, 105-118.

Ferretti, F., Adornetti, I., Chiera, A., Nicchiarelli, S., Valeri, G., Magni, R., ... Marini, A. (2018). Time and narrative: An investigation of storytelling abilities in children with autism spectrum disorder. Frontiers in Psychology, 9, 944.

Ferretti, F., \& Adornetti, I. (2012). Dalla comunicazione al linguaggio: Scimmie, ominidi e umani in una prospettiva darwiniana. Milano: Mondadori Università.

Ferretti, F., \& Adornetti, I. (2020). Why we need a narrative brain to account for the origin of language. Paradigmi, $38(2), 269-292$.

Ferretti, F., \& Adornetti, I. (2021). Persuasive conversation as a new form of communication in Homo sapiens. Philosophical Transactions of the Royal Society B, 376(1824), 20200196. https://doi.org/10.1098/rstb.2020. 0196 
Ferretti, F., Adornetti, I., \& Chiera, A. (submitted). Narrative pantomime: A protolanguage for persuasive communication.

Fitzpatrick, S. E., Srivorakiat, L., Wink, L. K., Pedapati, E. V., \& Erickson, C. A. (2016). Aggression in autism spectrum disorder: Presentation and treatment options. Neuropsychiatric Disease and Treatment, 12, 15251538.

Fukase, H., Kondo, O., \& Ishida, H. (2015). Size and placement of developing anterior teeth in immature Neanderthal mandibles from Dederiyeh Cave, Syria: Implications for emergence of the modern human chin. American Journal of Physical Anthropology, 156, 482-488. https://doi.org/10.1002/ajpa.22665

Fusaroli, R., Rączaszek-Leonardi, J., \& Tylén, K. (2014). Dialog as interpersonal synergy. New Ideas in Psychology, 32, 147-157. https://doi.org/10.1016/j.newideapsych.2013.03.005

Gamble, C. S. (1996). Making tracks: Hominid networks and the evolution of the social landscape. In J. Steele \& S. J. Shennan (Eds.), The archaeology of human ancestry: Power, sex and tradition (pp. 253-277). London: Routledge.

Gamble, C. S. (1999). The Palaeolithic societies of Europe. Cambridge: Cambridge University Press.

Gilbert, D. T., Krull, D. S., \& Malone, P. S. (1990). Unbelieving the unbelievable: Some problems in the rejection of false information. Journal of Personality and Social Psychology, 59, 601-613.

Gilbert, D. T., Tafarodi, R. W., \& Malone, P. S. (1993). You can't not believe everything you read. Journal of Personality and Social Psychology, 65(2), 221-233.

Givón, T. (1979). On understanding grammar. New York: Academic Press.

Gleeson, B. T., \& Kushnick, G. (2018). Female status, food security, and stature sexual dimorphism: Testing mate choice as a mechanism in human self-domestication. American Journal of Physical Anthropology, 167(3), 458469. https://doi.org/10.1002/ajpa.23642.

Greenfield, M. D. (2002). Signalers and receivers: Mechanisms and evolution of arthropod communication. Oxford: Oxford University Press.

Grice, H. P. (1957). Meaning. The Philosophical Review, 66(3), 377-388.

Grice, P. (1975). Logic and conversation. In P. Cole \&J. Morgan (Eds.), Syntax and semantics. Vol 3: Speech acts (pp. 41-58). New York: Academic Press.

Happé, F. G. (1993). Communicative competence and theory of mind in autism: A test of relevance theory. Cognition, 48(2), 101-119.

Happé, F. G. (1994). An advanced test of theory of mind: Understanding of story characters' thoughts and feelings by able autistic, mentally handicapped, and normal children and adults. Journal of Autism and Developmental Disorders, 24(2), 129-154.

Happé, F. G. (1995). The role of age and verbal ability in the theory of mind task performance of subjects with autism. Child Development, 66, 843-855.

Hare, B. (2017). Survival of the friendliest: Homo sapiens evolved via selection for prosociality. Annual Review of Psychology, 68, 155-186. https://doi.org/10.1146/annurev-psych-010416-044201

Hare, B., Wobber, V., \& Wrangham, R. (2012). The self-domestication hypothesis: Evolution of bonobo psychology is due to selection against aggression. Animal Behavior, 83(3), 573-585.

Hausberger, M., Henry, L., Testé, B., \& Barbu, S. (2008). Contextual sensitivity and bird song: A basis for social life. In K. Oller \& U. Griebel (Eds.), Evolution of communication flexibility: Complexity, creativity, and adaptability in human and animal communication (pp. 121-138). Cambridge, MA: MIT Press.

Hauser, M. D. (1996). The evolution of communication. Cambridge, MA: MIT Press.

Hawhee, D. (2011). Toward a bestial rhetoric. Philosophy and Rhetoric, 44(1), 81-87.

Hawhee, D. (2017). Rhetoric in tooth and claw: Animals, language, sensation. Chicago: University of Chicago Press.

Heine, B., \& Kuteva, T. (2007). The genesis of Grammar. Oxford: Oxford University Press.

Henry, L., Craig, A. J., Lemasson, A., \& Hausberger, M. (2015). Social coordination in animal vocal interactions. Is there any evidence of turn-taking? The starling as an animal model. Frontiers in Psychology, 6, 1416. https: //doi.org/10.3389/fpsyg.2015.01416 
Hernádi, A., Kis, A., Turcsán, B., \& Topál, J. (2012). Man’s underground best friend: Domestic ferrets, unlike the wild forms, show evidence of dog-like social-cognitive skills. Plos One, 7, e43267.

Herrmann, E., Hare, B., Cissewski, J., \& Tomasello, M. A. (2011). Comparison of temperament in nonhuman apes and human infants. Developmental Science, 14, 1393-1405.

Heyes, C. M., \& Frith, C. D. (2014). The cultural evolution of mind reading. Science, 344(6190), 1243091. https: //doi.org/10.1126/science.1243091

Heyes, C. (2018). Cognitive gadgets: The cultural evolution of thinking. Cambridge, MA: Harvard University Press.

Heyes, C. (2020). Culture. Curr Biol., 30(20), R1246-R1250. https://doi.org/10.1016/j.cub.2020.08.086

Hill, A. P., Zuckerman, K. E., Hagen, A. D., Kriz, D. J., Duvall, S. W., van Santen, J., Nigg, J., Fair, D., \& Fombonne, E. (2014). Aggressive behavior problems in children with autism spectrum disorders: prevalence and correlates in a large clinical sample. Research in Autism Spectrum Disorders, 8, 1121-1133.

Hirota, T., Deserno, M., \& McElroy, E. (2020). The network structure of irritability and aggression in individuals with autism spectrum disorder. Journal of Autism and Developmental Disorders, 50, 1210-1220.

Hoefler, S., \& Smith, A. D. M. (2009). The pre-linguistic basis of grammaticalisation: A unified approach to metaphor and reanalysis. Studies in Language, 33, 883-906.

Holler, J., Casillas, M., Kendrick, K. H., \& Levinson, S. C. (Eds.) (2016). Turn-taking in human communicative interaction. Lausanne, Switzerland: Frontiers Media.

Hopper, P. J., \& Traugott, E. C. (2003). Grammaticalization. Cambridge: Cambridge University Press.

Huang, S., Slomianka, L., Farmer, A. J., Kharlamova, A. V., Gulevich, R. G., Herbeck, Y. E., Trut, L. N., Wolfer, D. P., \& Amrein, I. (2015). Selection for tameness, a key behavioral trait of domestication, increases adult hippocampal neurogenesis in foxes. Hippocampus, 25(8), 963-975. https://doi.org/10.1002/hipo.22420

Jones, C. D., \& Schwartz, I. S. (2009). When asking questions is not enough: An observational study of social communication differences in high functioning children with autism. Journal of Autism and Developmental Disorders, 39(3), 432-443.

Jordan, R. (2010). Autism spectrum disorders: An introductory handbook for practitioners. Oxfordshire: David Fulton Publishers.

Kano, F., \& Hirata, S. (2015). Great apes make anticipatory looks based on longtermmemory of single events. Current Biology, 25(19), 2513-2517, https://doi.org/10.1016/j.cub.2015.08.004

Kano, F., Krupenye, C., Hirata, S., Tomonaga, M., \& Call, J. (2019). Great apes use self-experience to anticipate an agent's action in a false-belief test. Proceedings of the National Academy of Sciences of the United States of America, 116(42), 20904-20909. https://doi.org/10.1073/pnas.1910095116

Kennedy, G. A. (1998). Comparative rhetoric: An historical and cross-cultural introduction. Oxford: Oxford University Press.

Kennedy, G. A. (1992). A hoot in the dark: The evolution of general rhetoric. Philosophy and Rhetoric, 25(1), $1-21$.

Kissel, M., \& Kim, N. C. (2019). The emergence of human warfare: Current perspectives. American Journal of Physical Anthropology, 168(Suppl 67), 141-163. https://doi.org/10.1002/ajpa.23751

Knight, C. (1998). Ritual/speech coevolution: A solution to the problem of deception. In J. R. Hurford, M. Studdert-Kennedy \& C. Knight (Eds.), Approaches to the evolution of language (pp. 68-91). Cambridge: Cambridge University Press.

Kobayashi, Y., Wakano, J. Y., \& Ohtsuki, H. (2019). Evolution of cumulative culture for niche construction. Journal of Theoretical Biology, 472, 67-76. https://doi.org/10.1016/j.jtbi.2019.04.013

Krebs, J. R., \& Dawkins, R. (1984). Animal Signals: Mind-reading and Manipulation. In Krebs, J. R. \& Davies, N. B. (Eds.), Behavioural ecology: An evolutionary approach (2nd ed., pp. 380-402). Sunderland, MA: Sinaur.

Krupenye, C., Kano, F., Hirata, S., Call, J., \& Tomasello, M. (2016). Great apes anticipate that other individuals will act according to false beliefs. Science, 354(6308), 110-114, https://doi.org/10.1126/science.aaf8110

Kruska, D. C. (1988). Mammalian domestication and its effects on brain structure and behaviour. In H. J. Jerison \& I. Jerison (Eds.), Intelligence and evolutionary biology (pp. 211-250). Berlin: Springer Verlag. 
Kruska, D. C. (2005). On the evolutionary significance of encephalization in some eutherian mammals: Effects of adaptive radiation, domestication, and feralization. Brain, Behavious and Evolution, 65, 73-108.

Lakoff, G., \& Johnson, M. (1980). Metaphors we live by. Chicago, IL: University of Chicago Press.

Laland, K., Odling-Smee, J., \& Feldman, M. (2000). Niche construction, biological evolution, and cultural change. Behavioral and Brain Sciences, 23(1), 131-146. https://doi.org/10.1017/S0140525X00002417

Laland, K. N., Odling-Smee, J., \& Myles, S. (2010). How culture shaped the human genome: Bringing genetics and the human sciences together. Nature Reviews Genetics, 11(2), 137-148.

Langley, M., Benítez-Burraco, A., \& Kempe, V. (2019). Playing with language, creating complexity: Has play contributed to the evolution of complex language? Evolutionary Anthropology, 29(1), 29-40. https://doi.org/ 10.1002/evan.21810

Lascarides, A., \& Asher, N. (2008). Segmented discourse representation theory: Dynamic semantics with discourse structure. In H. Bunt \& R. Muskens (Eds.), Computing meaning (Vol. 3, pp. 87-124). Dordrecht: Springer.

Lavenex, P., \& Banta Lavenex, P. (2013). Building hippocampal circuits to learn and remember: insights into the development of human memory. Behavioural Brain Research, 254, 8-21. https://doi.org/10.1016/j.bbr.2013. 02.007

Leach, H. M. (2003). Human domestication reconsidered. Current Anthropology, 44, 349-368

Leech, G. (1983). Principles of pragmatics. London: Longman.

Levinson, S. C. (2016). Turn-taking in human communication-origins and implications for language processing. Trends in Cognitive Sciences, 20(1), 6-14. https://doi.org/10.1016/j.tics.2015.10.010

Lewis, D. K. (1969). Conventions. Cambridge, MA: Harvard University Press.

Lewis, J. D., Theilmann, R. J., Townsend, J., \& Evans, A. C. (2013). Network efficiency in autism spectrum disorder and its relation to brain overgrowth. Frontiers in Human Neuroscience, 7, 845. https://doi.org/10. 3389/fnhum.2013.00845

Lind, S. E., \& Bowler, D. M. (2010). Episodic memory and episodic future thinking in adults with autism. Journal of Abnormal Psychology, 119(4), 896.

Lindgren, K., Folstein, S., Tomblin, J. B., \& Tager-Flusberg, H. (2009). Language and reading abilities of children with autism spectrum disorders and specific language impairment and their first-degree relatives. Autism Research, 2, 22-38.

Lindström, J. (2009). Interactional linguistics. In S. D’hondt, J. -O. Östman \& J. Verschueren (Eds.), The pragmatics of interaction (pp. 96-103). Philadelphia, PA: John Benjamins.

Locke, J. L. (2008). Cost and complexity: Selection in language and speech. Journal of Theoretical Biology, 251, $640-652$.

Lord, K. A., Larson, G., Coppinger, R. P., \& Karlsson, E. K. (2020). The history of farm foxes undermines the animal domestication syndrome. Trends in Ecology \& Evolution, 35(2), 125-136. https://doi.org/10.1016/j.tree. 2019.10.011

Lupyan, G., \& Dale, R. (2010). Language structure is partly determined by social structure. Plos One, 5(1), e8559. https://doi.org/10.1371/journal.pone.0008559

Maguire, E. A., Burgess, N., Donnett, J. G., Frackowiak, R. S., Frith, C. D., \& O’Keefe, J. (1998). Knowing where and getting there: a human navigation network. Science, 280(5365), 921-924. https://doi.org/10.1126/science. 280.5365 .921

Maguire, E. A., Intraub, H., \& Mullally, S. L. (2016). Scenes, spaces, and memory traces: What does the hippocampus do? The Neuroscientist, 22(5), 432-439, https://doi.org/10.1177/1073858415600389

Marini, A., Ferretti, F., Chiera, A., Magni, R., Adornetti, I., Nicchiarelli, S., ... Valeri, G. (2019). Episodic future thinking and narrative discourse generation in children with Autism Spectrum Disorders. Journal of Neurolinguistics, 49, 178-188.

Marini, A., Ferretti, F., Chiera, A., Magni, R., Adornetti, I., Nicchiarelli, S., ... Valeri, G. (2016). Brief report: Self-based and mechanical-based future thinking in children with autism spectrum disorder. Journal of Autism and Developmental Disorders, 46(10), 3353-3360.

Marsh, P. (1978). Aggro: The illusion of violence. London: Dent. 
Mason, R. A., Williams, D. L., Kana, R. K., Minshew, N., \& Just, M. A. (2008). Theory of Mind disruption and recruitment of the right hemisphere during narrative comprehension in autism. Neuropsychologia, 46(1), 269-280. https://doi.org/10.1016/j.neuropsychologia.2007.07.018

Mathieson, I., Alpaslan-Roodenberg, S., Posth, C., Szécsényi-Nagy, A., Rohland, N., Mallick, S., ... Reich, D. (2018). The genomic history of southeastern Europe. Nature, 555(7695), 197-203. https://doi.org/10.1038/ nature 25778

Maynard Smith, J., \& Harper, D. (2003). Animal signals. Oxford: Oxford University Press.

McEwen, B. S., Eiland, L., Hunter, R. G., \& Miller, M. M. (2012). Stress and anxiety: structural plasticity and epigenetic regulation as a consequence of stress. Neuropharmacology, 62, 3-12.

Mercier, H. (2020). Not born yesterday: The science of who we trust and what we believe. Princeton, NJ: Princeton University Press.

Mercier, H., \& Sperber, D. (2017). The enigma of reason. Cambridge, MA: Harvard University Press.

Mercier, H., \& Sperber, D. (2009). Intuitive and reflective inferences. In J. Evans \& K. Frankish (Eds.), In two minds (pp. 149-170). Oxford: Oxford University Press.

Michaelian, K. (2016). Mental time travel: Episodic memory and our knowledge of the personal past. Cambridge, MA: MIT Press.

Milligan, K., Astington, J. W., \& Dack, L. A. (2007). Language and theory of mind: Meta-analysis of the relation between language ability and false-belief understanding. Child Development, 78(2), 622-646.

Mithen, S. (1996). The prehistory of the mind. London: Thames and Hudson.

Moore, R. (2017). Social cognition, stag hunts, and the evolution of language. Biology \& Philosophy, 32(6), 797818. https://doi.org/10.1007/s10539-017-9598-7

Moore, R. (2020). The cultural evolution of mind-modelling. Synthese, 1-26. https://doi.org/10.1007/ s11229-020-02853-3

Mulcahy, N. J., \& Call, J. (2006). Apes save tools for future use. Science, 312(5776), 1038-1040, https://doi.org/ $10.1126 /$ science. 1125456

Nanay, B. (2020). Vicarious representation: A new theory of social cognition. Cognition, 205, 104451.

Nordahl, C. W., Lange, N., Li, D. D., Barnett, L. A., Lee, A., Buonocore, M. H., Simon, T. J., Rogers, S., Ozonoff, S., \& Amaral, D. G. (2011). Brain enlargement is associated with regression in preschool-age boys with autism spectrum disorders. Proceedings of the National Academy of Sciences of the United States of America, 108(50), 20195-200. https://doi.org/10.1073/pnas.1107560108

Norbury, C. F. (2004). Factors supporting idiom comprehension in children with communication disorders. Journal of Speech, Language, and Hearing Research, 47, 1179-1193.

O'Driscoll, J. (1996). About face: A defence and elaboration of universal dualism. Journal of Pragmatics, 25(1), $1-32$.

Obafemi-Ajayi, T., Miles, J. H., Takahashi, T. N., Qi, W., Aldridge, K., Zhang, M., Xin, S. Q., He, Y., \& Duan, Y. (2015). Facial structure analysis separates autism spectrum disorders into meaningful clinical subgroups. Journal of Autism and Developmental Disorders, 45(5), 1302-1317. https://doi.org/10.1007/s10803-014-2290-8

Ochi, K., Ono, N., Owada, K., Kojima, M., Kuroda, M., Sagayama, S., \& Yamasue, H. (2019). Quantification of speech and synchrony in the conversation of adults with autism spectrum disorder. Plos One, 14(12), e0225377. https://doi.org/10.1371/journal.pone.0225377

Okanoya, K. (2017). Sexual communication and domestication may give rise to the signal complexity necessary for the emergence of language: An indication from songbird studies. Psychonomic Bulletin \& Review, 24, $106-110$.

Origgi, G., \& Sperber, D. (2000). Evolution, communication and the proper function of language. In P. Carruthers $\&$ A. Chamberlain (Eds.), Evolution and the human mind: Language, modularity and social cognition (pp. 140-169). Cambridge: Cambridge University Press.

Owren, M. J., Rendall, D., \& Ryan, M. J. (2010). Redefining animal signaling: Influence versus information in communication. Biology and Philosophy, 25(5), 755-780.

Parkinson, C., \& Wheatley, T. (2015). The repurposed social brain. Trends in Cognitive Sciences, 19(3), 133-141. https://doi.org/10.1016/j.tics.2015.01.003 
Parrish, A. C. (2013). The (instinctual) art of persuasion. The Evolutionary Review, 4(1), 57-66.

Parrish, A. C. (2014). Adaptive rhetoric: Evolution, culture, and the art of persuasion. New York: Routledge.

Perkins, M. (2007). Pragmatic impairment. Cambridge: Cambridge University Press.

Pika, S., Wilkinson, R., Kendrick, K. H., \& Vernes, S. C. (2018). Taking turns: Bridging the gap between human and animal communication. Proceedings of the Royal Society B, 285, 20180598. http://doi.org/10.1098/rspb. 2018.0598

Pinker, S., Nowak, M. A., \& Lee, J. J. (2008). The logic of indirect speech. Proceedings of the National Academy of Sciences, 105(3), 833-838.

Pisor, A. C., \& Surbeck, M. (2019). The evolution of intergroup tolerance in nonhuman primates and humans. Evolutionary Anthropology, 28(4), 210-223.

Plavcan, J. M. (2012). Sexual size dimorphism, canine dimorphism, and male-male competition in primates: Where do humans fit in? Human Nature, 23(1), 45-67. https://doi.org/10.1007/s12110-012-9130-3

Pleyer, M. (2017). Protolanguage and mechanisms of meaning construal in interaction. Language Sciences, 63, 69-90.

Preissler, M. A. (2008). Associative learning of pictures and words by low-functioning children with autism. Autism, 12, 231-248.

Progovac, L. (2016). A gradualist scenario for language evolution: Precise linguistic reconstruction of early human (and Neandertal) grammars. Frontiers in Psychology, 7, 1714. https://doi.org/10.3389/fpsyg.2016.01714

Progovac, L., \& Locke, J. L. (2009). The urge to merge: Ritual insult and the evolution of syntax. Biolinguistics, $3(2-3), 337-354$.

Progovac, L., \& Benítez-Burraco, A. (2019). From physical aggression to verbal behavior: Language evolution and self-domestication feedback loop. Frontiers in Psychology, 10, 2807. https://doi.org/10.3389/fpsyg.2019.02807

Rakhlin, N., \& Progovac, L. (2020). Hierarchical clause structure as a tool for cognitive advances in early childhood. Language Sciences, 83, 101316. Retrieved from http://doi.org/10.1016/j.langsci.2020.101316

Raviv, L., Meyer, A., \& Lev-Ari, S. (2019). Larger communities create more systematic languages. Proceedings of the Royal Society B, 286, 20191262. http://doi.org/10.1098/rspb.2019.1262

Raviv, L., Meyer, A., \& Lev-Ari, S. (2020). The role of social network structure in the emergence of linguistic structure. Cognitive Science, 44(2020), e12876. https://doi.org/10.1111/cogs.12876

Reboul, A. (2017). Cognition and communication in the evolution of language. Oxford: Oxford University Press.

Rehkämper, G., Frahm, H. D., \& Cnotka, J. (2008). Mosaic evolution and adaptive brain component alteration under domestication seen on the background of evolutionary theory. Brain Behavior and Evolution, 71, 115126.

Sacco, R., Gabriele, S., \& Persico, A. M. (2015). Head circumference and brain size in autism spectrum disorder: A systematic review and metaanalysis. Psychiatry Research, 234(2), 239-251. https://doi.org/10.1016/j. pscychresns.2015.08.016

Sacks, H. (2014). Turn-taking in conversations. In J. Angermuller, D. Maingueneau \& R. Wodak (Eds.), The discourse studies reader: Main currents in theory and analysis (pp. 194-293). Amsterdam: John Benjamins.

Sacks, H., Schegloff, E. A., \& Jefferson, G. (1974). A simplest systematics for the organization of turn-taking for conversation. Language, 50(4), 696-735.

Sala, N., Arsuaga, J. L., Pantoja-Pérez, A., Pablos, A., Martínez, I., Quam, R. M., ... Carbonell, E. (2015). Lethal interpersonal violence in the Middle Pleistocene. Plos One, 10(5), e0126589. https://doi.org/10.1371/journal. pone. 0126589

Sánchez-Villagra, M. R., \& van Schaik, C. P. (2019). Evaluating the self-domestication hypothesis of human evolution. Evolutionary Anthropology, 28(3), 133-143. https://doi.org/10.1002/evan.21777

Sato, T., \& Wakebe, T. (2012). Selecting a relevant mental state in young children's persuasion. Psychological Studies, 57(1), 67-74.

Schegloff, E. A. (1997). Whose text? Whose context?. Discourse and Society, 8(2), 165-187.

Schilder, B. M., Petry, H. M., \& Hof, P. R. (2020). Evolutionary shifts dramatically reorganized the human hippocampal complex. Journal of Comparative Neurology, 528(17), 3143-3170. https://doi.org/10.1002/cne. 24822 
Schultz, R. T., Grelotti, D. J., Klin, A., Kleinman, J., Van der Gaag, C., Marois, R., \& Skudlarski, P. (2003). The role of the fusiform face area in social cognition: Implications for the pathobiology of autism. Philosophical Transactions of the Royal Society of London. Series B: Biological Sciences, 358(1430), 415-427.

Scott-Phillips, T. (2015). Speaking our minds: Why human communication is different, and how language evolved to make it special. Basingstoke, Hampshire: Palgrave Macmillan.

Scott-Phillips, T. C. (2017). Pragmatics and the aims of language evolution. Psychonomic Bulletin \& Review, 24(1), 186-189. https://doi.org/10.3758/s13423-016-1061-2

Senft, G. (2018). Theory meets practice -H. Paul Grice's Maxims of Quality and Manner and the Trobriand Islanders' language use. In A. Capone, M. Carapezza \& F. Lo Piparo (Eds.), Further advances in pragmatics and philosophy (Vol. 18, pp. 203-220). Cham: Springer International Publishing. https://doi.org/10.1007/ 978-3-319-72173-6_10

Seyfarth, R. M., Cheney, D. L., Bergman, T., Fischer, J., Zuberbühler, K., \& Hammerschmidt, K. (2010). The central importance of information in studies of animal communication. Animal Behaviour, 80(1), 3-8.

Shannon, C. E., \& Weaver, W. (1949). The mathematical theory of communication. Urbana: University of Illinois Press.

Shea, B. (1989). Heterochrony in human evolution: The case for neoteny reconsidered. American Journal of Physical Anthropology, 32, 69-101.

Sheppard, D. P., Bruineberg, J. P., Kretschmer-Trendowicz, A., \& Altgassen, M. (2018). Prospective memory in autism: Theory and literature review. The Clinical Neuropsychologist, 32(5), 748-782. https://doi.org/10.1080/ 13854046.2018.1435823

Shilton, D., Breski, M., Dor, D., \& Jablonka, E. (2020). Human social evolution: Self-domestication or selfcontrol? Frontiers in Psychology, 11, 134. https://doi.org/10.3389/fpsyg.2020.00134

Sidnell, J. (2011). Conversation analysis: An introduction. Malden, MA: John Wiley and Sons.

Sidnell, J. (2001). Conversational turn-taking in a Caribbean English Creole. Journal of Pragmatics, 33(8), 1263 1290. https://doi.org/10.1016/S0378-2166(00)00062-X

Sinha, C. (2015). Language and other artifacts: Socio-cultural dynamics of niche construction. Frontiers in Psychology, 6, 1601. https://doi.org/10.3389/fpsyg.2015.01601

Slaughter, V., Peterson, C. C., \& Moore, C. (2013). I can talk you into it: Theory of mind and persuasion behavior in young children. Developmental Psychology, 49(2), 227.

Smith, K. (2011). Learning bias, cultural evolution of language, and the biological evolution of the language faculty. Human Biology, 83(2), 261-278. https://doi.org/10.3378/027.083.0207

Smith, A. D. M. (2011). Grammaticalization and language evolution. In B. Heine \& H. Narrog (Eds.), The Oxford handbook of grammaticalization (pp. 142-152). Oxford: Oxford University Press.

Smith, A. D. M., \& Höfler, S. (2014). The pivotal role of metaphor in the evolution of human language. In J. E. Diaz Vera (Ed.), Metaphor and metonymy across time and cultures. Berlin: Mouton de Gruyter.

Sng, Y. C., Carter, M., \& Stephenson, J. (2018). A systematic review of the comparative pragmatic differences in conversational skills of individuals with autism. Autism and Developmental Language Impairments, 3, 1-24.

Somel, M., Franz, H., Yan, Z., Lorenc, A., Guo, S., Giger, T., ... Khaitovich, P. (2009). Transcriptional neoteny in the human brain. PNAS, 106(14), 5743-5748. https://doi.org/10.1073/pnas.0900544106

Spelke, E. (2003). What makes us smart? In D. Gentner \& S. Goldin-Meadow (Eds.), Language in mind (pp. 277-311). Cambridge, MA: MIT Press.

Spelke, E. S., \& Kinzler, K. D. (2007). Core knowledge. Developmental Science, 10(1), 89-96. https://doi.org/10. 1111/j.1467-7687.2007.00569.x

Sperber, D. (2001). An evolutionary perspective on testimony and argumentation. Philosophical Topics, 29, 401413

Sperber, D., Clément, F., Heintz, C., Mascaro, O., Mercier, H., Origgi, G., \& Wilson, D. (2010). Epistemic vigilance. Mind \& Language, 25(4), 359-393.

Sperber, D., \& Wilson, D. (1986). [1995²]. Relevance: Communication and cognition.. Oxford: Blackwell.

Sperber, D., \& Wilson, D. (2002). Pragmatics, modularity and mind-reading. Mind \& Language, 17, 1-2, 3-23, https://doi.org/10.1111/1468-0017.00186 
Sperber, D. (2000). Metarepresentations in an evolutionary perspective. In D. Sperber (Ed.), Metarepresentations: An interdisciplinary perspective (pp. 117-138). Oxford: Oxford University Press.

Spikins, P., French, J. C., John-Wood, S., \& Dytham, C. (2021). Theoretical and methodological approaches to ecological changes, social behaviour and human intergroup tolerance 300,000 to 30,000 BP. Journal of Archaeological Method and Theory, 28(1), 53-75. https://doi.org/10.1007/s10816-020-09503-5

Spratt, E. G., Nicholas, J. S., Brady, K. T., Carpenter, L. A., Hatcher, C. R., Meekins, K. A., Furlanetto, R. W., \& Charles, J. M. (2012). Enhanced cortisol response to stress in children in autism. Journal of Autism and Developmental Disorders, 42, 75-81.

Steels, L. (2017). Human language is a culturally evolving system. Psychonomic Bulletin \& Review, 24(1), 190193. https://doi.org/10.3758/s13423-016-1086-6

Stringer, C. (2016). The origin and evolution of Homo sapiens. Philosophical Transactions of the Royal Society of London. Series B: Biological Sciences, 371, 20150237.

Suddendorf, T., Addis, D. R., \& Corballis, M. C. (2009). Mental time travel and the shaping of the human mind. Philosophical Transactions of the Royal Society B: Biological Sciences, 364(1521), 1317-1324

Suddendorf, T., \& Corballis, M. C. (1997). Mental Time Travel and the Evolution of the Human Mind. Genetic Social and General Psychology Monographs, 123(2), 133-167. https://doi.org/10.1017/S0140525.07001975

Syal, S., \& Finlay, B. L. (2011). Thinking outside the cortex: Social motivation in the evolution and development of language. Developmental Science, 14, 417-430.

Tager-Flusberg, H. (2006). Defining language phenotypes in autism. Clinical Neuroscience Research, 6, 219-224.

Tager-Flusberg, H., Paul, R., \& Lord, C. (2005). Language and communication in autism. In F. R. Volkmar, R. Paul, A. Klin \& D. Cohen (Eds.), Handbook of autism and pervasive developmental disorders (pp. 335-364). New York: Wiley.

Tamariz, M., \& Kirby, S. (2016). The cultural evolution of language. Current Opinion in Psychology, 8, 37-43. https://doi.org/10.1016/j.copsyc.2015.09.003

Taylor, J. L, \& Corbett, B. A. (2014). A review of rhythm and responsiveness of cortisol in individuals with autism spectrum disorders. Psychoneuroendocrinology, 49, 207-228.

Theofanopoulou, C., Gastaldon, S., O'Rourke, T., Samuels, B. D., Martins, P. T., Delogu, F., .. Boeckx, C. (2017). Self-domestication in Homo sapiens: Insights from comparative genomics. Plos One, 12(10), e0185306. https: //doi.org/10.1371/journal.pone.0185306

Terrett, G., Rendell, P. G., Raponi-Saunders, S., Henry, J. D., Bailey, P. E., \& Altgassen, M. (2013). Episodic future thinking in children with autism spectrum disorder. Journal of Autism and Developmental Disorders, 43(11), 2558-2568.

Theofanopoulou, C., Gastaldon, S., O’Rourke, T., Samuels, B. D., Messner, A., Martins, P. T., Delogu, F., Alamri, S., \& Boeckx, C.. (2017). Self-domestication in Homo sapiens: Insights from comparative genomics. Plos One, 12, $\mathrm{e} 0185306$.

Thomas, J., \& Kirby, S. (2018). Self domestication and the evolution of language. Biology and Philosophy, 33(1), 9. https://doi.org/10.1007/s10539-018-9612-8

Thompson, S. A., \& Couper-Kuhlen, E. (2005). The clause as a locus of grammar and interaction. Discourse Studies, 7(4-5), 481-505. https://doi.org/10.1177/1461445605054403

Thompson, S. A., Fox, B. A., \& Couper-Kuhlen, E. (2015). Grammar in everyday talk: Building responsive actions. Cambridge: Cambridge University Press.

To, C. K., Yim, S. F., Lam, G. Y., \& Iao, L. S. (2016). Persuasion in Chinese school-age children with and without autism spectrum disorders. Focus on Autism and Other Developmental Disabilities, 31(3), 231-240.

Tomasello, M. (2008). Origins of human communication. Cambridge, MA: MIT Press.

Toro, R., Konyukh, M., Delorme, R., Leblond, C., Chaste, P., Fauchereau, F., ... Bourgeron, T. (2010). Key role for gene dosage and synaptic homeostasis in autism spectrum disorders. Trends in Genetics, 26, 363-372.

Trinkaus, E. (2012). Neandertals, early modern humans, and rodeo riders. Journal of Archaeological Science, 39(12), 3691-3693. https://doi.org/10.1016/j.jas.2012.05.039.

Tulving, E. (1985). Elements of episodic memory. Oxford: Clarendon Press. 
Tulving, E.. (2007). “Are There 256 Different Kinds of Memory?” in J S. Nairne (ed.), The Foundations of Remembering, New York: Psychology Press.

Udell, M. A. (2015). When dogs look back: Inhibition of independent problem-solving behaviour in domestic dogs (Canis lupus familiaris) compared with wolves (Canis lupus). Biology Letters, 11(9), 20150489.

van Daalen, E., Swinkels, S. H., Dietz, C., van Engeland, H., \& Buitelaar, J. K. (2007). Body length and head growth in the first year of life in autism. Pediatric Neurology, 37, 324-330.

Vanier, D. R., Sherwood, C. C., \& Smaers, J. B. (2019). Distinct Patterns of hippocampal and neocortical evolution in primates. Brain Behavior and Evolution, 93(4), 171-181. https://doi.org/10.1159/000500625

Vinogradova, O. S. (2001). Hippocampus as comparator: role of the two input and two output systems of the hippocampus in selection and registration of information. Hippocampus, 11(5), 578-598. https://doi.org/10. 1002/hipo.1073

Volden, J. (2004). Conversational repair in speakers with autism spectrum disorder. International Journal of Language and Communication Disorders, 39(2), 171-189.

Volden, J. (2017). Autism spectrum disorder. In L. Cummings (Ed.), Research in clinical pragmatics (pp. 59-83). Cham, Switzerland: Springer.

Wacewicz, S. (2015). The shades of social. A discussion of "The social origins of language", ed. Daniel Dor, C K and J Lewis. Theoria et Historia Scientiarum, 11, 191-208.

Wacewicz, S., Żywiczyński, P., \& Chiera, A. (2017). An evolutionary approach to low-level conversational cooperation. Language Sciences, 63(2017), 91-104.

Walenski, M., Tager-Flusberg, H., \& Ullman, M. (2006). Language in autism. In S. O. Moldin \& J. L. R. Rubenstein (Eds.), Understanding autism: From basic neuroscience to treatment (pp. 175-203). Boca Raton: Taylor and Francis Books.

Wang, A. T., Lee, S. S., Sigman, M., \& Dapretto, M. (2006). Neural basis of irony comprehension in children with autism: The role of prosody and context. Brain, 129(4), 932-943.

Wang, A. T., Lee, S. S., Sigman, M., \& Dapretto, M. (2007). Reading affect in the face and voice: Neural correlates of interpreting communicative intent in children and adolescents with autism spectrum disorders. Archives of General Psychiatry, 64(6), 698-708.

Wacewicz, S., \& Żywiczyński, P. (2018). Language origins: Fitness consequences, platform of trust, cooperation, and turn-taking. Interaction Studies, 19(1-2), 167-182.

Wilkins, A. S., Wrangham, R. W., \& Fitch, W. T. (2014). The "domestication syndrome" in mammals: A unified explanation based on neural crest cell behavior and genetics. Genetics, 197(3), 795-808. https://doi.org/10. 1534/genetics.114.165423

Wilson, M. L., Boesch, C., Fruth, B., Furuichi, T., Gilby, I. C., Hashimoto, C., ... Wrangham, R. W. (2014). Lethal aggression in Pan is better explained by adaptive strategies than human impacts. Nature, 513(7518), 414-417. https://doi.org/10.1038/nature13727.

Wragg Sykes, R. M. (2012). Neanderthals 2.0. Evidence for expanded social networks, ethnic diversity and encultured landscapes in the Late Middle Palaeolithic. In K. Ruebens, I. Romanowska \& R. Bynoe (Eds.), Unravelling the Palaeolithic-Ten years of research at the Centre for the Archaeology of Human Origins (CAHO, University of Southampton) (Vol. 2400, pp. 73-84). Oxford: British Archaeological Reports.

Wrangham, R. W., \& Glowacki, L. (2012). Intergroup aggression in chimpanzees and war in nomadic huntergatherers. Human Nature, 23, 5-29.

Wrangham, R. W. (2018). Two types of aggression in human evolution. PNAS, 115(2), 245-253.

Wright, D., Henriksen, R., \& Johnsson, M.(2020). Defining the domestication syndrome: Comment on Lord et al. 2020. Trends in Ecology \& Evolution, 35(12), 1059-1060. https://doi.org/10.1016/j.tree.2020.08.009.

Woensdregt, M., Cummins, C., \& Smith, K. (2020). A computational model of the cultural co-evolution of language and mindreading. Synthese, https://doi.org/10.1007/s11229-020-02798-7

Wray, A., \& Grace, G. W. (2007). The consequences of talking to strangers: Evolutionary corollaries of sociocultural influences on linguistic form. Lingua, 117, 543-578.

Wynn, T., \& Coolidge, F. (2011). How to think like a Neanderthal. Oxford: Oxford University Press. 
Xu, C., Li, Q., Efimova, O., He, L., Tatsumoto, S., Stepanova, V., Oishi, T., Udono, T., Yamaguchi, K., Shigenobu, S., Kakita, A., Nawa, H., Khaitovich, P., \& Go, Y. (2018). Human-specific features of spatial gene expression and regulation in eight brain regions. Genome Research, 28(8), 1097-1110. https://doi.org/10.1101/gr.231357. 117

Zollikofer, C. P. E., \& Ponce de León, M. S. (2010). The evolution of hominin ontogenies. Seminars in Cell \& Developmental Biology, 21, 441-452.

Zufferey, S. (2015). Acquiring pragmatics. Social and cognitive perspectives. London: Routledge. 